\title{
Apoptosis Review Series
}

\section{Regulation of apoptosis by the ubiquitin and proteasome pathway}

\author{
Cezary Wójcik ${ }^{a, b} *$ \\ a Department of Histology and Embryology, Center of Biostructure Research, \\ Medical University of Warsaw, Warsaw, Poland \\ ${ }^{b}$ Department of Physiology, University of Texas Southwestern Medical Center, Dallas, Texas, USA
}

Received: March 14, 2002; Accepted: March 28, 2002

- Introduction

- The ubiquitin and proteasome pathway of protein degradation

- Ubiquitin

- Proteasome

- Proteasome inhibitors

- Involvement of the ubiquitin and proteasome pathway in apoptosis

- Proteasome inhibitors as inducers of apoptosis

- Possible mechanisms of proapototic action of proteasome inhibitors

- Proteasome inhibitors can also inhibit apoptosis

- Targets of proteasome-dependent

degradation during apoptosis
- Components of the proteasome system degraded by caspases

- Role of deubiquitinating enzymes in apoptosis

- Involvement of cell differentiation in the susceptibility to apoptosis caused by proteasome inhibitors

- Accumulation of ubiquitinated proteins as a possible trigger of apoptosis

- Heat shock protein in proteasome inhibitorinduced apoptosis

- Proteasome inhibitors in cancer therapy

- Combination of proteasome inhibitors with other proapoptotic agents

- Resistance to the proapoptotic action of proteasome inhibitors

- Concluding remarks

\begin{abstract}
Regulated proteolysis plays important roles in cell physiology as well as in pathological conditions. In most of the cases, regulated proteolysis is carried out by the ubiquitin- and proteasome-dependent proteolytic system, which is also in charge of the bulk of cytoplasmic proteolysis. However, apoptosis or the process of programmed cell death is regulated by a different proteolytic system, i.e. by caspases, a family of specialized cysteine proteases. Nevertheless, there is plenty of evidence of a crosstalk between the apoptotic pathways and the ubiquitin and proteasome system, whose function in apoptosis appears to be very complex. Proteasome inhibitors induce apoptosis in multiple cell types, while in other they are relatively harmless or even prevent apoptosis induced by other stimuli. Proteasomes degrade specific proteins during apoptosis, but on the other hand some components of the proteasome system are degraded by caspases. The knowledge about the involvement of the ubiquitin- and proteasome-dependent system in apoptosis is already clinically exploited, since proteasome inhibitors are being tested as experimental drugs in the treatment of cancer and other pathological conditions, where manipulation of apoptosis is desirable.
\end{abstract}

Keywords: apoptosis - caspases - proteasome - proteolysis - ubiquitin

*Correspondence to: Dr. Cezary WÓJCIK Department of Histology and Embryology, Center of Biostructure Research, Warsaw Medical Academy, ul. Chalubinskiego 5, 02-004 Warsaw, Poland

Phone/Fax: +(48 22) 6295282 ,

E-mail: cwojcik@ib.amwaw.edu.pl 


\section{Introduction}

By sacrificing the life of individual cells for the sake of a multicellular organism as a whole, apoptosis mediates the proper development of our organisms, prevents the emergence of autoimmune clones of T cells, prevents the proliferation of cells with damaged genetic material, and constitutes one of the first lines of defense in the fight against malignancies. Recent years have seen great advances in the molecular dissection of the apoptotic pathways. Despite the plethora of diverse proapototic stimuli, the execution of apoptosis involves a common stage consisting on the activation of caspases, a family of cytoplasmic cystein proteases which cleave after aspartate residues. Caspase-dependent cleavages selectively inhibit some proteins, while activate another, which in turn leads to the phenotype characteristic of apoptotic cells. Apoptosis is therefore an example of a pathway tightly regulated by specific cytoplasmic proteolysis.

Regulated cytoplasmic proteolysis governs multiple biochemical pathways [1]. Caspases constitute an exception to the rule, since in most of the cases regulated cytoplasmic proteolysis is mediated by the $26 \mathrm{~S}$ proteasome, a huge cytosolic multicatalytic complex, considered by some a bona fide organelle [2]. Proteasomes not only selectively degrade specific regulatory proteins, but they also mediate the bulk of intracellular proteolysis [3]. It has been noted, that loss-of-function mutations of proteasome components in yeast lead to a lethal phenotype, which can be mimicked in mammalian cells by the use of specific proteasome inhibitors [4]. This effect was expected, taking into account the importance of the ubiquitin- and proteasomedependent degradation pathway. However, further studies revealed the rather striking observation that at least in some circumstances proteasome inhibition in mammalian cells may lead to a totally opposite effects, i.e. it generates a pro-survival signal. This observations arose with detailed studies of the possible role of the proteasome in apoptosis, which will be discussed in the present review. Several reviews of a similar scope have been published recently and the reader is referred to them for a different point of view on the same broad subject $[5,6,7,8,9]$.

\section{The ubiquitin and proteasome pathway of protein degradation}

Intracellular protein degradation was once considered to be a rather simple process, carried out by the lysosomal enzymes. Since the hydrolysis of a peptide bond is a thermodynamically favored reaction, the discovery of an ATP-dependent system of protein degradation in reticulocyte lysates was rather surprising [10]. It eventually leads to the molecular dissection of the ubiquitin- and proteasome-dependent system of protein degradation [11].

\section{Ubiquitin}

Most proteins which are going to be degraded by the proteasome are first tagged with several moieties of a small, 76-amino acid polypeptide called ubiquitin. Ubiquitin also have some roles not related to proteolysis, which are probably evolutionarily more ancient. Those roles include covalent modification of histones [12], internalization of plasma membrane proteins [13] and chaperoning the biogenesis of ribosomes [14]. Ubiquitin was identified as the temperature-stable factor needed to reconstitute in vitro the ATPdependent proteolytic system from reticulocyte lysates [15].

Ubiquitin is present in all studied eukaryotic cells and tissues. It is coded either as polyubiquitin genes or as ribosomal fusion proteins. Its sequence is one of the most conserved since the yeast ubiquitin sequence differs from human only in 3 out of 76 amino acids [16]. Proteins can be modified by covalent attachment of a variant number of ubiquitin moieties, a reaction which is known as ubiquitination (or ubiquitinylation). Ubiquitin is usually attached by an isopeptide bond between the C-terminal Gly residue of ubiquitin and an amino group of internal Lys residues of the substrate, however it can be also attached to the $\alpha$-amino group of the $\mathrm{N}$-terminal amino acid [17]. Ubiquitin itself can be a substrate of ubiquitination, since it contains several Lys residues. This reaction produces polyubiquitin chains of variable lengths, which are usually linked through Lys 48, however other Lys within ubiquitin are also used for conjugation $[18,19]$. 
Ubiquitination reaction is carried out by the E1E2-E3 cascade of enzymes. E1 is the ubiquitinactivating enzyme (UBA), which activates ubiquitin forming a highly energetic thiolester with the use of ATP. Subsequently, ubiquitin is transferred to one of the different E2s or ubiquitin conjugating enzymes (UBC). The latter, either alone or in association with additional multisubunit enzymes, called ubiquitin ligases or E3s, transfer the ubiquitin moiety to the substrate $[16,18]$. Proteins tagged with polyubiquitin chains are recognized and bound by the $26 \mathrm{~S}$ proteasomes, which subsequently degrade them into small peptides. In some instances, proteins are targeted for degradation by alternate tagging mechanisms, including binding to adaptor proteins (e.g. antizyme
[20]) or covalent modification by ubiquitin-like proteins, such as Nedd8 [21]. The ubiquitination cascade leading to the degradation of the substrate by the $26 \mathrm{~S}$ proteasome is depicted in Fig. 1.

This pathway is further complicated by the existence of numerous deubiquitinating enzymes (DUBs). DUBs cleave not only the polyubiquitin chains and ribosomal ubiquitin fusion proteins generated from respective genes, but also the polyubiquitin chains generated by the E1-E2-E3 cascade. The latter, can be either free chains released from tagged substrates which have been already degraded by proteasomes, or they can be chains bound to undegraded substrates. In the latter case, DUBs can perform an editing or rescue function $[22,23]$.

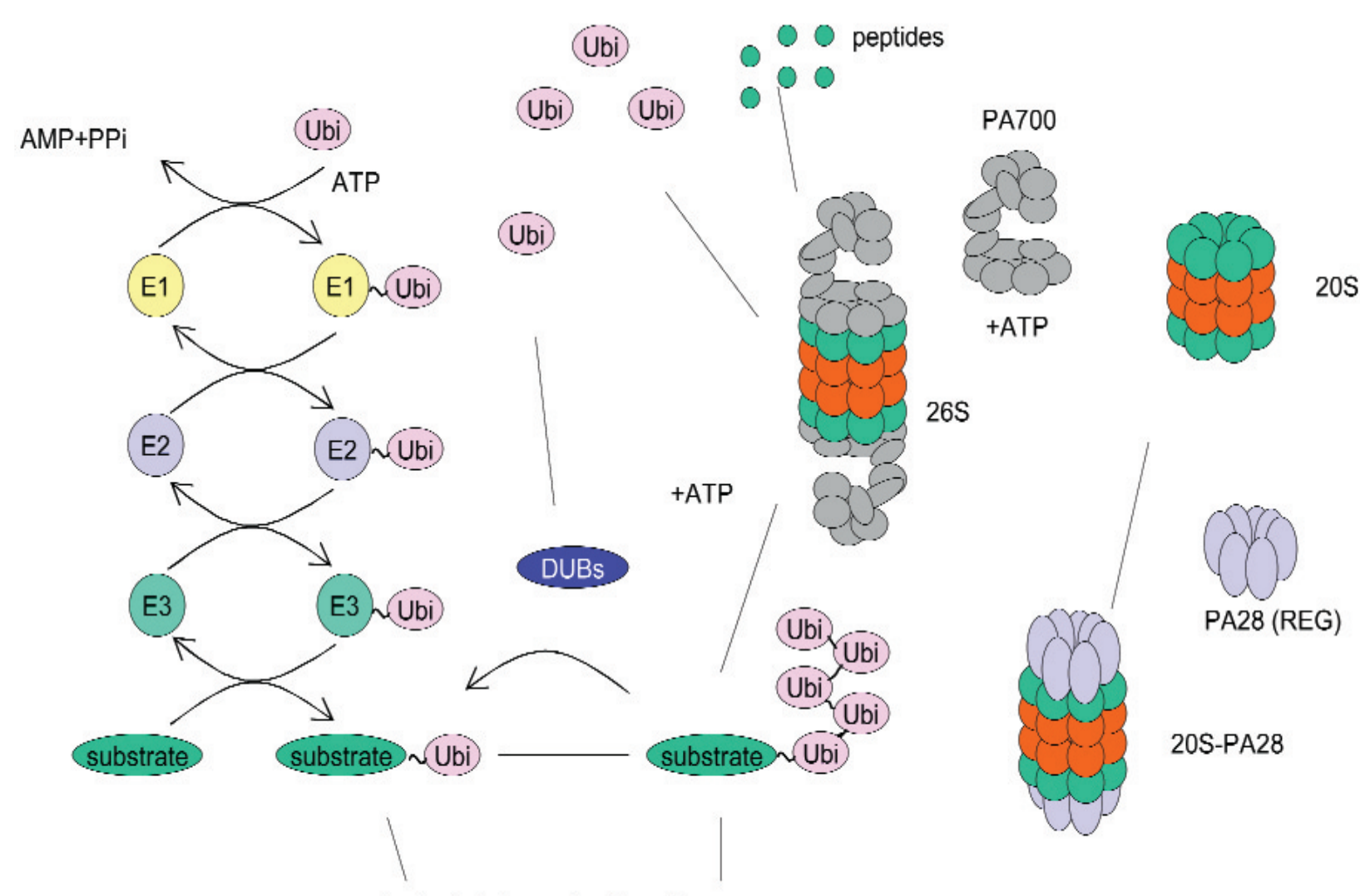

proteolysis-independent functions

Fig. 1 Schematic overview of the ubiquitin-proteasome pathway. E3 enzymes recognize substrates and mediate the transfer of ubiquitin from an E2. The latter receives its ubiquitin by transfer from an E1. Polyubiquitinated proteins are targeted for degradation by the $26 \mathrm{~S}$ proteasome. Mono- and polyubiquitinated proteins can be deubiquitinated by the action of numerous deubiquitinating enzymes (DUBs). The $26 \mathrm{~S}$ proteasome releases free ubiquitin and degrades the substrate to short peptides. The $26 \mathrm{~S}$ multicatalytic proteinase complex is made up of the core 20S proteasome and PA700 activator (19S cap). 20S proteasome can also associate with PA28 (REG) activators, but this complex can not degrade ubiquitinated proteins and its function is still not clear. 


\section{Proteasome}

Proteasomes are ubiquitous and abundant ( $\sim 1 \%$ of total cell protein [24]) intracellular multicatalytic enzymes responsible for the degradation of most cellular proteins [3]. They are present not only in all eukaryotic cells studied, but also in Archeabacteria and even in some Eubacteria. The name "proteasome" coined by Arrigo et al. in 1988 [25] designates two different molecular species: the $26 \mathrm{~S}$ proteasome, which is the fully active organelle, capable of degrading ubiquitinated proteins, and its catalytic core, the $20 \mathrm{~S}$ proteasome. The latter by itself is unable to degrade cellular proteins, however it can cleave some short peptides and unfolded proteins [26,27]. The yeast $20 \mathrm{~S}$ proteasome have been crystallized, and its structure is solved with the $2.4 \AA$ resolution [28].

$20 \mathrm{~S}$ proteasomes were first identified in extracts of bovine pituitary as a cation-sensitive neutral endopeptidase [29]. Further studies revealed, that it was a $\sim 700 \mathrm{kDa}$ multisubunit complex with three different hydrolytic activities cleaving peptides at the carboxyl side of hydrophobic, basic, and acidic residues. Those activities were named chymotrypsin-like (ChTL), trypsin-like (TL) and postglutamyl peptide hydrolyzing (PGPH) respectively. The new enzyme was called multicatalytic proteinase complex (MPC) [30,31].

$20 \mathrm{~S}$ proteasomes are cylindrical structures made up from four stacked rings, arranged as a complex dimer according to a $\mathrm{C} 2$ symmetry. Each ring is made up from seven subunits: the inner rings are called $\beta$ rings, while the outer are called $\alpha$ rings. In Archeabacteria the $\alpha$ rings are made up of seven identical $\alpha$ subunits, while the $\beta$ rings are made up of seven identical $\beta$ subunits. Eukaryotic proteasomes are made up of fourteen different subunits classified into seven $\alpha$ and seven $\beta$ type subunits, which are homologous to the respective two subunits present in Archeabacteria [32,28,26]. Three different $\beta$ subunits have free $\mathrm{N}$-terminal Thr residues, which are responsible for the proteolytic activity $[33,34]$. In archeabacterial proteasomes the distal parts of the $\alpha$ rings are open, allowing the access of substrates into the central catalytic chamber through a channel, which penetrates along the central axis of the proteasome [32]. However, in yeast proteasomes the $\mathrm{N}$-terminal extensions of the $\alpha$ subunits occlude the entrance to the inner cavities of the proteasome, which can be reached only by small peptides [28].

Mammals have three additional proteasome subunits called LMP2, LMP7 and MECL1. They are induced by interferon $\gamma$ and bear the catalytic $\mathrm{N}$ terminal Thr residues. Upon the action of interferon $\gamma$, these subunits are incorporated into the newly made proteasomes instead of their constitutive counterparts (called tradionally X, Y and Z) [35]. Proteasomes with INF $\gamma$-inducible subunits are referred to as immunoproteasomes. They produce a different spectrum of peptides than constitutive proteasomes. Peptides produced by either proteasomes or immunoproteasomes are transported through the TAP transporter complex into the ER lumen, where they can be further trimmed by aminopeptidases and assembled into MHC class I molecules [36,37].

The 26S proteasome is formed by the association of the $20 \mathrm{~S}$ proteasome with two particles of the PA700 proteasome activator (also called the 19S cap) [38]. PA700 can be further subdivided into the base and the lid. The base is made up mainly of six distinct ATP-ases of the AAA family which tightly associate with the $\alpha$ ring of the proteasome, while the lid is formed by less characterized proteins localized distally [39,40]. The functions of the PA700 complex consist in the recognition of the polyubiquitinated substrate, liberation of the polyubiquitin chain, unfolding of the substrate, opening of the central proteasome channel and translocation of the unfolded polypeptide chain towards the catalytic sites. Other protein complexes also associate with the $20 \mathrm{~S}$ proteasome. One of them is the PA28 activator, made up of different but closely related $\alpha$ and $\beta$ subunits, which are induced by interferon $\gamma$. When associated with $20 \mathrm{~S}$ proteasome, PA28 greatly enhances its peptidase activity but not the protein degradation [41,42]. It has been implicated in the processing of MHC class I antigens [43]. Hybrid proteasomes, with PA28 attached to one end of the $20 \mathrm{~S}$ particle and PA700 to the other have also been described. An activator different from PA28 $\alpha \beta$ is the PA28 $\gamma$, which is downregulated by interferon $\gamma$ [44]. An inhibitor of the proteasome has also been described [45].

Independently on their study as proteolytic enzymes, proteasomes have also been described as "prosomes" which formed ribonucleoprotein 
complexes and were supposed to regulate mRNA distribution in cells $[25,46]$. It now seems, that the association of mRNA with proteasomes is rather a bystanding phenomenon without major significance [47].

\section{Proteasome inhibitors}

The proteasome has been tested with numerous protease inhibitors in order to find out, into which protease family it belongs. The identity and nature of its catalytic sites has remained unclear for a long time until the discovery, that it belongs to a novel class of N-terminal threonine proteases [33,48].

Several recent reviews detailing the properties and mechanisms of action of proteasome inhibitors are available [49,50,51]. Each of the proteolytic activities of the proteasome can be inhibited independently, e.g. the ChTL activity is inhibited by aldehyde analogs of the transition state of the substrate and 3,4-dichloroisocoumarin, while the TL activity is blocked by leupeptin and sulfhydryl blocking agents [30,30,52]. Subsequently, it was found out, that the ChTL activity is rate limiting for efficient protein degradation [3], and therefore most new inhibitors were designed to block it.

A rational approach to design proteasome inhibitors consisted in the modicfication of peptide proteasome substrates with different C-terminal groups, like aldehydes, epoxyketones, boronic acids, vinyl sulfones etc. Two peptide aldehydes which are still used widely in different experimental systems are PSI [53] and MG132 [3]. Different pharmaceutical companies developed further derivatives, which are more specific and have better solubility and bioavailability $[54,55,56]$. The leader of the race towards an clinically usable proteasome inhibitor is Millennium Pharmaceuticals, which developed boronic acid derivatives. The most potent of them is PS-341 (Fig. 2). It has good oral potency and long half life ( $24 \mathrm{~h}$ in rats) with low sytematic toxicity. It is currently undergoing phase II clinical trials in terminal cancer patients [57].

Several new inhibitors have been reported recently. Eponemycin and epoximycin (Fig. 2) have been described originally as anticancer agents produced by a Streptomyces strain, but later have

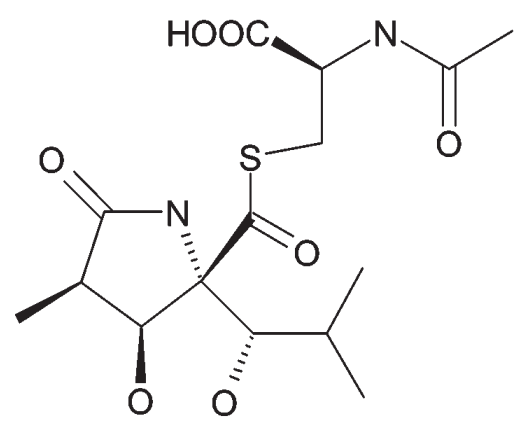

lactacystin<smiles>CC(C)C[C@H](NC(=O)C(Cc1ccccc1)NC(=O)c1cnccn1)B(O)O</smiles>

PS-341

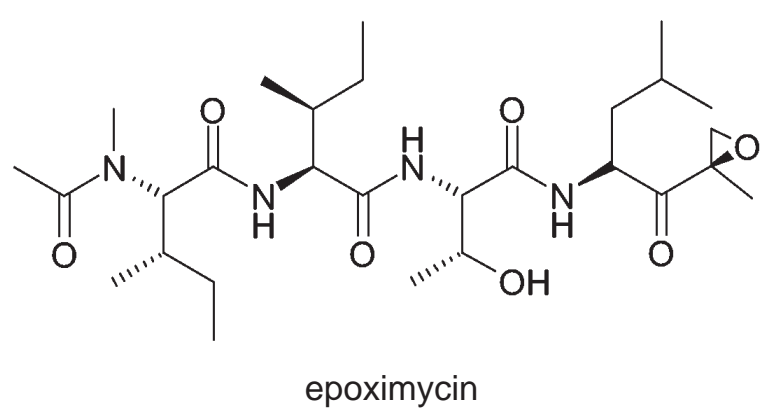

Fig. 2 Structural formulas of selected proteasome inhibitors, known to cause apoptosis in numerous cell types. 
been found to be bona fide proteasome inhibitors. They are covalently modifying the catalytically active $\mathrm{N}$-terminal $\mathrm{Thr}$ residues of $\beta 5$ and $\beta 2$ subunits, what results in a strong inhibition of the ChTL activity, and a much weaker inhibition of the PGPH and TL activities [58,59]. Gliotoxin, a fungal metabolite responsible for various toxic effects accompanying Aspergillus fumigatus and Candida albicans infections is also an effective inhibitor of the proteasome [60]. Several other antibiotics inhibiting the different activities of the proteasome have also been described. Tannic acid, which is commonly present in human diet (e.g. in the tea) inhibits the chymotrypsin-like activity of the proteasome, causing cell cycle block and apoptosis. This finding explains its anticancer activity [61].

Various drugs used in clinical practice, have been shown to interact with the ubiquitinproteasome pathway of protein degradation. The inhibitor of the HIV protease Ritonavir is also a potent inhibitor of the ChTL activity of the proteasome [62]. Lovastatin, an inhibitor of the hydroxymethyl glutaryl-coenzyme A reductase used commonly to lower cholesterol plasma levels also partially inhibits some proteasome activities $[63,64]$. Widely used chemotheraputics, have been shown to be also inhibitors of the ubiquitinproteasome degradation pathway. Cisplatin inhibits the ubiquitination of proteins, while aclacinomycin $\mathrm{A}$ and mitomycin $\mathrm{C}$ are not interfering with ubiquitination but inhibit the degradation of ubiquitinated proteins $[65,66,67]$. Doxorubicin binds to the proteasome without inhibiting it [68]. Vinblastine inhibits proteasome activity in vitro and causes accumulation of ubiquitinated proteins in vivo besides its effect on microtubules [69].

\section{Involvement of the ubiquitin and proteasome pathway in apoptosis}

The nineties of the last century have seen an unprecedented explosion of general interest in the ubiquitin- and proteasome-dependent pathway of protein degradation, which has been found linked to almost every area of molecular biological study. Taking into account the importance of apoptosis it is not astounding, that the evidence of crosstalk between those pathways came relatively early. First indication of the involvement of the ubiquitin- and proteasome pathway in apoptosis was from the study of programmed cell death in intersegmental muscles in the larval hawkmoth Manduca sexta, where a dramatic increase of polyubiquitin gene expression ocurred [70]. Details of those pioneering studies are described elsewhere [8].

\section{Proteasome inhibitors as inducers of apoptosis}

The first detailed description of apoptosis induced by a specific proteasome inhibitor was done in 1995, when Imajoh-Ohmi and colleagues published a report, showing that lactacystin induces apoptosis of human leukemia U937 cells [71]. Several other studies followed using different set of inhibitors and several different cell lines (for references see $[8,5])$.

The fact, that proteasome inhibitors caused apoptosis was not surprising, since regulated proteolysis performs very important roles in various biochemical pathways including cell cycle control and regulation of gene expression. It was found out, that proteasome inhibitors are potent inducers of apoptosis, since they are able to induce apoptosis in cells which are resistant to other agents. For instance, different proteasome inhibitors, including lactacystin and MG132 potently induce apoptosis in leukaemic B cells from patients with B cell chronic lymphocytic leukaemia (B-CLL) at all stages of the disease, including those resistant to conventional chemotherapy [72].

\section{Possible mechanisms of proapototic action of proteasome inhibitors}

It was assumed, that proteasome inhibitors induce apoptosis either by general toxic effects or by their virtue to prevent degradation and/or processing of specific regulatory proteins. Pre-treatment of B-cell chronic lymphocytic leukaemia cells with a cell permeable caspase inhibitor before treatment with proteasome inhibitors does not prevent the release of cytochrome c, formation of apoptosome and partial processing of caspase-9 but prevents activation of effector caspases and the induction of apoptosis. These results suggest that the release of cytochrome $\mathrm{c}$ is caspase independent and that 
caspase- 9 is the initiator caspase in proteasome inhibitor-induced apoptosis [72]. Bcl-2 has been shown to antagonize PSI-induced apoptosis induced in human myeloid leukaemia cell lines [73]. In pancreatic cancer cells PS-341 treatment decrease Bcl-2 expression, without effect on Bax or Bak. The downregulation of Bcl-2 by PS-341 appears to be transcriptionally mediated [74]. Overexpression of $\mathrm{Bcl}-2$ induces an increase in proteasome activity [75]. These results imply that Bcl-2 may be the main regulator of the effects of proteasome inhibitors.

One of the important effects of proteasome inhibitors is their ability to inhibit the degradation of $I \kappa B \alpha$ and therefore to prevent the activation of $\mathrm{NF \kappa B}[76]$. After the stimulation with various cytokines, NFKB activation is involved in the stimulation of the pro-survival pathway and prevention of apoptosis. TNF $\alpha$ can induce in a single cell at the same time a proapoptotic signal and a prosurvival signal mediated by NFKB activation. The latter often masks the proapoptotic signal, however prevention of NFKB activation by proteasome inhibitors unmasks it and leads to apoptosis $[77,78,79,80,81]$.

NFKB induction can protect some cell types from insults otherwise resulting in apoptosis. For example, pigment epithelium-derived factor (PEDF) protects immature cerebellar granule cells against apoptosis and mature cells against glutamate toxicity probably through NFKB activation. The protective effects of PEDF against both induced apoptosis and glutamate toxicity are blocked by addition of a proteasome inhibitor.[82]. A similar situation can be observed in eosinophils, where proteasome inhibitors render them susceptible to the proapoptotic action of TNF $\alpha$. This fact has important clinical implications, since selective inhibitors of $\mathrm{NF \kappa B}$ activation in eosinophils may be effective drugs in asthma and other allergic conditions [80]. Indeed, proteasome inhibitors have proven effective in an animal model of asthma [83].

Another mechanism of action of proteasome inhibitors involves the induction of a block in the cell cycle, which is usually generalized and involves all phases $[84,85]$ which are regulated by cellular proteolysis of either cyclins or CDK inhibitors [86]. While in some situations blocking the cell cycle can actually prevent the cells from entering apoptosis, in other situations the block in the cell cycle coexist or precedes the induction of apoptosis. Apoptosis can be triggered when the cells are unable to progress through the cell cycle despite the constant exposure to mitogens. For example PS341 blocks mitogen induced proliferation of BxPC3 human pancreatic cancer cells in vitro, while arresting cell cycle progression and inducing apoptosis by $24 \mathrm{~h}$. The CDK inhibitor p21 Cip1, accumulates correlating with cell cycle arrest [87].

Another protein whose stabilization by proteasome inhibitors may be responsible for induction of apoptosis is p53. p53 is the "guardian of genome integrity" since it elicits block in the cell cycle, DNA repair and eventually apoptotic response after stress insults compromising genomic integrity, oncogene activation and hypoxia. p53 is acting as a transcriptional regulator inducing expression of several crucial genes mediating those effects $[88,89,90]$. p53 levels are normally very low in the cells, since it is constantly ubiquitinated by Mdm2 RING-finger ubiquitin ligase and then degraded by the proteasome [91]. Mdm2 also ubiquitinates itself, what targets its for degradation by proteasomes during apoptosis even in absence of active p53, while it is also cleaved by caspase- 3 in p53-mediated apoptosis [92].

In situations of cellular stress p53 degradation is stopped and its levels rapidly rise. Proteasome inhibition induces usually p53 accumulation within cells, which may be resposible for the induction of apoptosis in the case of proliferating cells with normal p53 [93]. However, there are numerous examples, that proteasome inhibitors induce apoptosis in cells lacking a functional p53 $[94,95,96]$. Senescent cells offer an example, where stabilization of p53 by proteasome inhibitors does play an important role. Senescent cells are normally unable to stabilize p53 in response to DNA damage and therefore to undergo p53-dependent apoptosis. Proteasome inhibitors stabilize p53 in old fibroblasts and restored their ability to undergo apoptosis [97]. p53 can probably also regulate the levels of some important proteins by enhancing their degradation by the ubiquitin and proteasome pathway. p53 suppresses the expression of cFLIP that potentially blocks apoptotic signaling in human colon cancer cell lines. Treating those cells with a specific inhibitor of the proteasome inhibits the 
decrease of cFLIP by p53, suggesting that p53 enhances the degradation of cFLIP via a ubiquitinproteasome pathway. p53-mediated downregulation of cFLIP may explain the potent sensitization of human cancer cells to the apoptotic suicide program induced by wild-type p53 gene transfer [98].

Proteasome inhibitors can also cause the accumulation of c-Myc. The c-Myc oncoprotein is a transcription factor which is a critical regulator of cellular proliferation involved in the induction of apoptosis. Deregulated expression of c-Myc is associated with many human cancers, including Burkitt's lymphoma. The c- Myc protein is normally degraded very rapidly by the ubiquitinproteasome pathway. c-Myc is significantly stabilized (two- to six-fold) in many Burkitt's lymphoma-derived cell lines, suggesting that aberrant c-Myc proteolysis may play a role in the pathogenesis of Burkitt's lymphoma [99]. c-Myc protein levels are also elevated in other cell types treated with proteasome inhibitors playing an important role in the induction of apoptosis. For example, in human glioma cells proteasome inhibitors cause elevation of c-Myc protein levels, which induces transiently FasL message, and expression of FasL protein in turn stimulates the Fas receptor-ligand apoptotic signaling pathway [100]. Similarly MG132 up-regulates Fas and FADD expression in human vascular smooth muscle cells sensitizing them to apoptosis caused by FAS-ligand [101].

Proteasome inhibitors also prevent the degradation of active caspase 3, which is ubiquitinated by the ubiquitin-protein ligase activity of XIAP. Inactive procaspase 3 is not ubiquitinated by XIAP and therefore not readily degraded by the proteasome pathway [102].

Overexpression of procaspases sensitizes ovarian cancer cells to the proapoptotic action of proteasome inhibitors [103]. This has important practical value, since agents increasing procaspase expression may be used in combination with proteasome inhibitor to potentiate their antitumor action. Indeed, AAF-cmk, a tripeptidyl peptidase II (TPP II) inhibitor previously shown to induce procaspase expression, sensitizes human leukemic cells to the proapoptotic action of proteasome inhibitors (Mlynarczuk et al., unpublished observations).

Finally some of the effects of proteasome inhibition may involve the regulation of the levels of specific second messenger molecules like cAMP or nitric oxide, which may in turn induce apoptosis. In human neutrophils, the ubiquitin- and proteasome-dependent system of protein degradation regulates the balance of pro-apoptotic and anti-apoptotic proteins which plays a key role in the powerful ability of cyclic AMP to delay neutrophil death [104]. At low doses proteasome inhibitors cause an increase in oxidative protein damage and lipid peroxydation in neuronal cell lines without inducing apoptosis. However, at higher doses, they induce apoptosis accompanied by oxidative DNA damage, decreased reduced glutathione levels and increased nitric oxide production mediated by nNOS. Inhibition of this enzyme decreased levels of apoptosis, indicating that cell death induced by proteasome inhibitors it is at least in part mediated by nitric oxide [105].

\section{Proteasome inhibitors can also inhibit apoptosis}

While proteasome inhibitors rapidly induce apoptosis in cycling cells, probably by causing a cell cycle block and compromising many metabolic pathways, differentiated and resting cells are resistant to the proapoptotic effects of proteasome inhibitors [106]. Moreover, at least in two well defined systems proteasome inhibitors prevents apoptosis. That is the case of glucocorticoiddependent apoptosis and apoptosis of neuronal cells $[107,108]$. In some situations, proteasome inhibitors may have opposing effects even in the same cells, where they may either enhance or prevent apoptosis. Pretreatment of non small cell lung carcinoma cells in culture with proteasome inhibitors prevents the proapoptotic action of topoisomerase inhibitors, while when proteasome inhibitors are administered after the treatment with topoisomerase inhibitors, they enhance their proapoptotic effect [109].

PSI blocks T cell receptor stimulation-induced apoptosis in a $\mathrm{T}$ cell hybridoma preventing the expression of Fas and Fas ligand and therefore preventing apoptosis. PSI also blocked extracellular signal-regulated kinase (ERK) activity induced by TCR stimulation, but had no effect on c-jun Nterminal kinase activation [110].

Apoptosis induced by glucocorticoids differ in many aspects from apoptosis induced by other 
stimuli including the involvement of proteasomes, which are dispensable e.g. in the FAS-mediated apoptotic pathway [111,112]. Proteasomes are known to regulate the overall cellular response to glucocorticoids, since upon ligand binding the glucocorticoid receptor becomes hyperphosphorylated and then it is ubiquitinated and degraded by proteasomes. Pretreatment of responsive cells with MG-132 or lactacystin effectively blocks glucocorticoid receptor protein down-regulation by dexamethasone. Proteasome inhibitors also enhance the transcriptional activity of the endogenous human glucocorticoid receptor in $\mathrm{HeLa}$ cells [113].

As reported by multiple groups, proteasome activity is involved at an early step of glucocorticoid-induced apoptosis, preceding mitochondrial changes and caspase activation [114]. It has been originally reported, that following dexamethasone treatment of thymocytes, ChTL activity of the proteasome decreases even in the presence of caspase inhibitors, without changes in the level of cellular proteasomes [108,115]. However, others have found, that dexamethasone induces rather an increase in the ChTL activity of the proteasome. While neither caspase inhibitors nor inhibitors of the mitochondrial permeability pore formation can prevent proteasome activation, it can be prevented by Bcl-2 overexpression, inhibitors of protein synthesis and antioxidants $[114,111]$.

\section{Targets of proteasome-dependent degradation during apoptosis}

Multiple targets of proteasome-mediated degradation during corticosteroid-induced apoptosis have been identified. They include transcription factors that regulate genes necessary for cell proliferation (e.g. c-Fos, NFkB, AP-1 $[116,117])$, enzymes whose activity is essential for cell proliferation (e.g. ornithine decarboxylase [118]), cell cycle regulatory proteins (e.g. p27 Kip1 [119]), and proteins that normally repress caspases (e.g. IAPs, inhibitors of apoptosis [120]). Since Bcl-2 have been reported to inhibit the increase in proteasome activity associated with corticosteroidinduced apoptosis, as well as degradation of c-Fos and p27 Kip1, the proteasome-mediated degradation of pro-survival factors may be an important control point by Bcl-2 [112]. Additional substrates have been identified in endothelial cells exposed to pro-apoptotic stimuli, such as lipopolysaccharide, TNF $\alpha$ and interleukin $1 \beta$ in the presence of cycloheximide, where proteasome inhibitors prevent apoptosis by blocking the degradation of antiapoptotic proteins FLIP and Mcl-1 [121].

The most important of all factors degraded by proteasomes during apoptosis may be the IAPs (inhibitors of apoptosis). IAPs are a family of proteins containing one or more characteristic BIR (baculovirus inhibitor of apoptosis) domains, which have multiple biological activities that include binding and inhibiting caspases, regulating cell cycle progression, and modulating receptormediated signal transduction. Several IAPs including XIAP and c-IAP1 in addition to three BIR domains contain a RING finger domain, which confers ubiquitin protease ligase (E3) activity. In response to an apoptotic stimulus IAPs undergo auto-ubiquitination and degradation. IAPs can bind a variety of proteins, such as caspases and TRAFs. They inactivate caspases by binding them and by targeting for degradation. Proteasome inhibitors promote cell survival by stabilizing the IAPs $[120,122,123]$.

\section{Components of the proteasome system degraded by caspases}

Recently it was shown, that during apoptosis induced by various stimuli caspase 6 specifically cleaves UFD2 producing an inactive $110 \mathrm{kDa}$ fragment from the whole length $130 \mathrm{kDa}$ protein. Moreover, the same specific cleavage can be induced by granzyme B [124]. Intriguingly, UFD2 is the human homologue of the yeast polyubiquitination factor (E4) Ufd2p [125]. Its function is lost in congenital DiGeorge and velocardio-facial syndromes [126]. Recombinant UFD2 has an in vitro ubiquitin ligase activity, which is lost after the caspase/granzyme mediated cleavage [124]. It is unknown what are the substrates of UFD2 in human cells and whether it performs a role similar to yeast E4. It is known, that UFD2 tightly binds to cytoplasmic chaperone/ATP-ase called p97 or VCP (valosin-containing protein). The latter is 
very similar to the ATP-ases forming the base of the 19S cap (PA700) of the $26 \mathrm{~S}$ proteasome and have a role in the degradation of selected ubiquitinated proteins [127], specially those exported from the ER [128]. Taking into account the fact, that it is induced by various stimuli in several cell lines, the inactivation of UFD2 during apoptosis may be an important event. It can be speculated, that UFD2 inactivation may prevent the ubiquitination and therefore proteasome-mediated degradation of a specific subset of substrates. It is tempting to speculate, that IAPs may be among UFD2 substrates.

Besides UFD2, another component of the ubiquitin- proteasome system which is cleaved by caspases during apoptosis is the proteasome activator PA28 $\gamma$. It was degraded by caspases-3 and -7 during FAS-induced apoptosis of HeLa cells and cisplatin-induced apoptosis of MCF7 cells [129]. It is difficult to judge at this point about the possible significance of this finding, since not much is known about the possible functions of PA28 $\gamma$ [44,130]. Knockout mice without PA28 $\gamma$ do not show detectable abnormalities, beside a mild growth retardation. PA28 $\gamma(-/-)$ embryonic fibroblasts are larger than their wild counterparts [131].

\section{Role of deubiquitinating enzymes in apoptosis}

Intracellular proteolysis by the ubiquitin- and proteasome pathway may be regulated at levels different than the inhibition of the proteasome itself. One of the limiting factors is the availability of free ubiquitin for the ubiquitination reaction, which is guaranteed by the concerted action of different deubiquitinating enzymes [23].

Targeting deubiquitinating enzymes may also be an effective way of inducing apoptosis. Prostaglandins of the $\mathrm{J}$ series cause apoptosis despite their inactivation of $\mathrm{p} 53$, because they inhibit the ubiquitin isopeptidase activity of the proteasome pathway. Inhibition of isopeptidases causes rapid depletion of the cells from free ubiquitin and accumulation of polyubiquitin chains, effectively inhibiting the ubiquitin- and proteasome-mediated degradation of most proteins [132].
Expression of the deubiquitinating enzyme DUB-2 markedly inhibits apoptosis induced by cytokine withdrawal allowing cells of the $\mathrm{Ba} / \mathrm{F} 3$ line to survive. Those cells have signs of constitutive activation of the IL-2 signalling pathway, with enhanced STAT5 phosphorylation and induced c-Myc expression. DUB-2 can enhance signaling through the JAK/STAT pathway, prolong lymphocyte survival, and, when constitutively expressed, may contribute to the activation of the JAK/STAT pathway observed in some transformed cells [133].

In situations of increased requirement for ubiquitin, this can be mobilized from intracellular pools, such as ubiquitinated histones. Nucleosomal histone $\mathrm{H} 2 \mathrm{~A}$ is usually mono-ubiquitinated ( $\mathrm{uH} 2 \mathrm{~A}$ ) [12]. Its deubiquitination is closely associated with mitotic chromatin condensation, although the exact function of this posttranslational change is unknown. Apoptosis induced in Jurkat cells by a variety of stimuli (including the activation of the FAS pathway, staurosporine, etoposide, doxorubicin and proteasome inhibitors) induces $\mathrm{uH} 2 \mathrm{~A}$ deubiquitination coincident with the onset of chromatin condensation. Moreover, histone deubiquitination is accompanied by a depletion of free ubiquitin and accumulation of high molecular weight ubiquitin conjugates. It could have been prevented with caspase inhibitors, what indicates that it is a downstream step during the execution phase of apoptosis rather than a determining or initiating apoptogenic event. Nucleosomal uH2A deubiquitination may function as a cellular sensor of stress in situations like apoptosis through which cells attempt to preserve genomic integrity [134].

\section{Involvement of cell differentiation in the susceptibility to apoptosis caused by proteasome inhibitors}

It has been observed, that often the degree of susceptibility to apoptosis depends on the level of differentiation of those cells. This phenomenon is observed in different systems. For example, in the retina of newborn rats proteasome inhibitor MG132 induces apoptosis of only a subpopulation of cells, while at later stages of development it does not induce apoptosis at all. MG132-sensitive population includes both proliferating cells most 
likely in their last round of cell division, and postmitotic undifferentiated cells, at a slightly earlier stage than the population, sensitive to cell death induced by the inhibitor of protein synthesis anisomycin [135].

The differential susceptibility of differentiated versus undifferentiated cells has practical implications in cancer treatment, since it accounts for the relatively low toxicity of proteasome inhibitors. For example, proteasome inhibitors are more active on leukemic than on normal CD34(+) bone marrow progenitors [136]. This effect may be mediated by the fact, that while the normal $\mathrm{CD} 34(+)$ bone marrow progenitors do not express NFKB the leukemic cells often do, and proteasome inhibitors prevent its activation.

During the process of differentiation specific proteins are degraded, because they are replaced by a set of different proteins characteristic of the differentiated cells. Therefore, by preventing that degradation, proteasome inhibitors can prevent the differentiation process itself. That is the case of mouse F9 embryonal carcinoma cells which under the action of retinoic acid differentiate into primitive endodermal type cells.Differentiation of F9 cells requires the action of the RAR and RXR receptors and is accompanied by growth inhibition, changes in cell morphology, increased apoptosis, induction of target genes and ubiquitin- and proteasome-dependent degradation of the RAR $\gamma 2$ receptor, and RNA polymerase II transcription factor TFIID subunits TBP and TAFII135. Similar events take place during the differentiation of rat C2C12 myotubes [137].

\section{Accumulation of ubiquitinated proteins as a possible trigger of apoptosis}

After considering a series of proteins whose accumulation can trigger apoptosis one must also consider the unspecific accumulation of ubiquitinated proteins within the cells as a possible apoptosis trigger. Accumulation of high molecular weight ubiquitin conjugates (usually in the form of an organized perinuclear aggregate or "aggresome") and depletion of monomeric ubiquitin is a characteristic feature of the treatment with proteasome inhibitors of diverse cell types $[138,139,140,141]$. Intriguingly several different apoptotic stimuli, like the activation of the FAS pathway, or treatment with drugs such as staurosporine, etoposide or doxorubicin, induce similar accumulation of high molecular weight ubiquitin conjugates and depletion of monomeric ubiquitin. Moreover, they induce deubiquitination of histone $\mathrm{H} 2 \mathrm{~A}$, which in turn is related to chromatin condensation. Those effects may be reverted by caspase inhibitors, indicating that they may be downstream effectors of apoptosis [134].

Despite the fact, that all cell types tested so far accumulate ubiquitin-conjugates upon the action of proteasome inhibitors, only some undergo apoptosis, but in many other cases they remain viable, indicating, that ubiquitin depletion and aggresome formation is not apoptogenic or cytotoxic per se, at least not in all cell types. Neuronal cells could be the cell type which is most susceptible to the accumulation of ubiquitinated proteins in form of organized aggregates, since several neurodegenerative disorders including Alzheimer's and Parkinson's diseases are characterized by neuronal apoptosis and the presence of intracellular ubiquitinated protein aggregates. However, it is also possible, that rather than a trigger of apoptosis, the formation of intracellular aggregates recruits otherwise toxic and/or apoptogenic proteins to a well delimited place, where they can be stored with less harm to the cells than in a dispersed form [142]. Accumulation of misfolded proteins induces a decrease in proteasome activity, probably by recruiting ubiquitin and proteasomes [143].

Apoptosis of neuronal cells have various distinguishing features. Bcl-2-dependent and caspase-mediated events account only partially for neurodegenerative changes in injured neurons. Blockage of the caspase execution machinery only temporarily rescues damaged neurons and classical apoptotic features can still appear in caspaseinhibited neurons which are characterized by cytochrome c release, chromatin condensation to irregularly shaped clumps, DNA- fragmentation, and exposure of phosphatidylserine. Inhibitors of the proteasome reduce these caspase-independent apoptotic-like features of the neuronal soma. [144].

A mysterious ubiquitin- binding protein p62 is up-regulated during apoptosis of Neuro-2a cells and cultured rat hippocampal neurons induced by different types of proapoptotic treatments, 
including serum deprivation, okadaic acid, etoposide, and trichostatin A. Moreover, different proteasomal inhibitors such as MG-132, lactacystin, and PSI caused a prominent upregulation of p62 mRNA and protein expression, with a concomitant increase in ubiquitinated proteins. The induction of p62 expression by proteasomal inhibitors may be a response to elevated levels of ubiquitinated proteins, possibly constituting a protective mechanism [145].

An indication about a possible toxicity of free polyubiquitin chains in the cells comes from studies of the ubiquitin- $\mathrm{B}+1 \quad(\mathrm{UBB}+1)$ mutant that accumulates in the neurons of patients with Alzheimer's disease (AD). UBB+1 lacks the capacity to ubiquitinate, and although it is ubiquitinated itself, UBB+1 is not degraded by the ubiquitin-proteasomal system and is quite stable in neuronal cells. Overexpression of $\mathrm{UBB}+1$ in neuroblastoma cells significantly induces nuclear fragmentation and cell death [146,147].

Expression of aggregation-prone proteins, such as mutant $\alpha$-synuclein in neuronal cell lines results in increased sensitivity to proteasome inhibitors, leading to mitochondrial abnormalities and apoptosis [148]. In some situations, ubiquitinated proteins and proteasomes accumulate not only in the cytoplasmic "aggresome" but also in nuclear inclusions, often identical with expanded PML (promyelocytic leukemia) nuclear bodies. For example, in the presence of proteasome inhibitors mutated forms of influenza virus nucleoprotein accumulates at both locations [149]. Another example of a situation when ubiquitinated abnormal proteins accumulate in nuclear inclusions are the polyglutamine diseases, such as Huntington's disease or spinal and bulbar muscular atrophy. They are inherited neurodegenerative diseases caused by the expansion CAG repeats (polyglutamine tract) within the coding region of target genes. The finding that nuclear inclusions found in those disorders are ubiquitinated raises the possibility that alterations in the ubiquitin-proteasome pathway, may be involved in the pathogenesis of polyglutamine diseases. Indeed, polyglutamine containing proteins are resistant to proteasome degradation. The longer the poly-Q repeat, the slower the degradation by the proteasome [150]. The shift of the proteasomal components from the total cellular environment to the nuclear aggregates, as well as the comparatively slower degradation of proteins with longer polyglutamine, decrease the proteasome's availability for degrading other key target proteins, such as p53. It was observed, that in a stable mouse neuro2a cell line that expresses truncated $\mathrm{N}$-terminal huntingtin with polyglutamine repeats altered proteasomal function was associated with disrupted mitochondrial membrane potential, released cytochrome $\mathrm{c}$ from mitochondria into the cytosol and activated caspase-9- and caspase-3-like proteases. These results suggest that the impaired proteasomal function plays an important role in polyglutamine protein-induced cell death [150].

\section{Heat shock protein in proteasome inhibitor- induced apoptosis}

When misfolded proteins appear in the cell as a result of an external stimulus such as heat shock or as the result of the expression of mutated proteins such as the polyglutamine repeat-bearing proteins, heat shock proteins or molecular chaperones are induced. They associate with the misfolded protein trying to refold it properly. If this fails, the misfolded protein is ubiquitinated and targeted for degradation by the proteasome mediated by its association with specialized adaptors such as CHIP and Bag-1 (see below). When there is an excess of unfolded proteins and not enough chaperones available, or when the proteasome activity is impaired, the unproperly folded proteins tend to aggregate recruiting the chaperones, proteasomes and ubiquitin in an insoluble compartment (Fig. 3) [151,152].

Bag-1 has been first identified as a supressor of apoptosis, which binds Bcl-2 [153]. Mammals possess several paralogues of this protein. All the Bag family members have a C-terminal BAG domain, which interacts with the ATP-ase domain of Hsp70 accelerating the ADP-ATP exchange and therefore stimulating substrate protein release [154]. Bag-1 and Bag-6 (Scythe, BAt3) have in addition to the BAG domain also an amino-terminal ubiquitin-like (UBL) domain. The UBL domain of Bag-1 mediates its association with the $26 \mathrm{~S}$ proteasome, and since it also binds Hsp70 it recruit this major Hsp to the proteasome [155]. Bag-1 can act as an unloading factor promoting direct delivery of unfolded proteins, substrates of Hsp70 activity, 


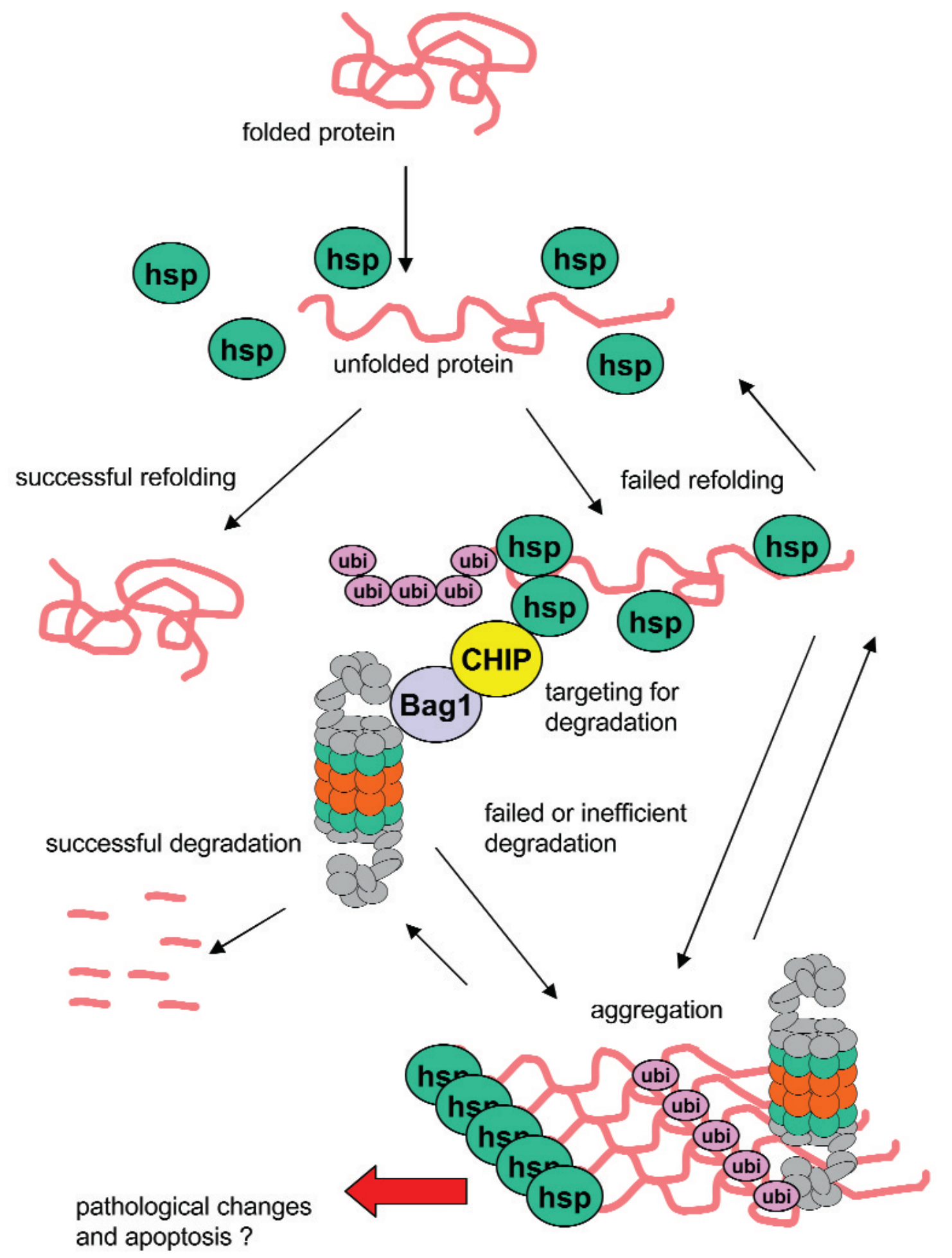

Fig. 3 Schematic representation of the fate of misfolded proteins within the cells. Misfolded proteins associate with molecular chaperones or heat shock proteins (hsp), which mediate their refolding. If the refolding fails, misfolded proteins are ubiquitinated and targeted for degradation by the 26Sproteasome with the help of accessory proteins, such as CHIP and Bag-1. Misfolded proteins have the tendency to aggregate, recruiting ubiquitin, proteasomes and heat shock proteins. It is not clear, whether the presence of organized aggregates protects the cell from the toxic effects of misfolded proteins or viceversa, it triggers apoptosis. 
for degradation. Bag-1 interacts with CHIP, an ubiquitin ligase interacting with Hsp70 and Hsp90, which mediates ubiquitination of unfolded proteins [156,157].

Proteasome inhibitors induce the expression of various molecular chaperones or heat shock proteins (HSPs), which are recruited by intracellular aggregates of ubiquitinated proteins, probably in an attempt to unfold and solubilize some of the aggregated proteins [158,159]. Curiously, the induction of molecular chaperones can be seprated from the effects of proteasome inhibitors on cell growth. It was shown, that from several proteasome inhibitors tested cancer cells were most sensitive to MG-132 and least sensitive to LLM. Induction of heat shock proteins, gp96 and HSP70 was, however, noted in response to LLM. Since LLM exhibited minimal cytotoxic effect, metabolic stress that results in induction of HSPs may not be translated in cell growth inhibition and there may exist a cell-type specific phenomenon in the HSP response to PI mediated metabolic stress [160].

Induction of molecular chaperones may prevent some deleterious effects caused by proteasome inhibitors, therefore preventing apoptosis. Indeed, overexpression of chaperones reduces aggregate formation and suppresses apoptosis in several polyglutamine disease models. These facts indicate that chaperones may be one of the key factors in the development of polyglutamine disease, and suggest that increasing expression level or enhancing the function of chaperones will provide an avenue for the treatment of polyglutamine disease [161].

Chaperones sometimes have also unwanted effects, including the protection of oncogenic or otherwise deleterious molecules from degradation by the proteasomes. For example, leukemic cells overexpressing Bcr-Abl such as HL60 or K562 cells display a high degree of resistance against antileukemic drug- induced apoptosis. Inhibition of the Hsp90 chaperone by geldanamycin or its analogues triggers apoptosis of those otherwise resistant cells. By binding and inhibiting Hsp90, geldanamycin treatment shifts the binding of BcrAbl from Hsp90 to Hsp70 and induces the proteasomal degradation of $\mathrm{Bcr}-\mathrm{Abl}$, because cotreatment with proteasome inhibitor PS341 inhibits apoptosis of HL-60/Bcr-Abl and K562 cells [162].

\section{Proteasome inhibitors in cancer therapy}

Induction of apoptosis in tumor cells and/or in nontumor cells supporting tumor growth such as endothelial cells is a prime goal in cancer therapy. Unfortunately, most stimuli known to induce apoptosis in cancer cells do it also in normal, healthy cells. Moreover, cancer cells usually are more resistant to apoptosis, due often to mutations in some components of the apoptotic machinery. The best example is p53, which is inactivated in more than $50 \%$ of human cancers. Another example is given by the gain-of-function mutations of genes such as Bcl-2 or Mdm2. However, proteasome inhibitors often selectively induce apoptosis in cancer cell lines, sparing normal cells [73]. Moreover, proteasome inhibitors are often able to induce apoptosis in cancer cell lines otherwise resistant to other agents [72]. PS341 currently undergoes phase II clinical trials for the treatment of multiple myeloma and other terminal cancer patients [163,164,57].

After numerous initial papers describing apoptosis in vitro elicited in various cancer cell lines, a series of in vivo experiments followed involving treatment of experimental cancer-bearing animals and evaluation of the effects of proteasome inhibitors on tumor burden, induction of apoptosis and survival. One of the first reports has shown, that an inhibitor of the ChTL activity of the proteasome induces tumor growth inhibition in nude mice bearing human Burkitt's lymphoma, which is associated with increased apoptosis of tumor cells [165]. Another group has demonstrated, that PSI prolongs the survival of mice bearing the murine colon carcinoma $\mathrm{C}-26$ by mechanisms involving decreased angiogenesis and p53 induction [166]. Afterwards, several other groups have published similar reports. PS-341 was found effective to inhibit growth of murine and human squamous cell carcinoma in mice. The mechanism of action of PS- 341 was found to involve the inhibition of NFKB pathway components related to cell survival, tumor growth, and angiogenesis in squamous cell carcinoma [167]. Treatment of human lung cancer A-549 tumor-bearing nude mice with the proteasome inhibitor CEP1612 resulted in massive induction of apoptosis and significant tumor growth inhibition, which was accompanied by the accumulation of two different CDK 
inhibitors, p21 Cip1 and p27KIP1 [168]. PS341 significantly inhibited the growth of BxPC3 and MIA-PaCa-2 human pancreatic cancer xenografts in nude mice, which was accompanied by increased apoptosis and p21Cip1 accumulation and downregulation of Bcl-2 [87,74].

It is very important to bear in mind, that the effects observed in vivo not always can be explained with in vitro assays and viceversa. Tumor cells grow in the extremely complex milieu formed by the multicellular organisms and interact with other cells. The clinical effects of every chemotherapeutic agent - including proteasome inhibitors - are the sum of the effects on the cancer cells and on the normal cells of the organisms, including endothelial and stromal cells. As it has been shown in some of the reports mentioned above, besides the direct effects on the tumor cells such as apoptosis induction, proteasome inhibitors also target normal endothelial cells preventing angiogenesis. Another example is given by the effects of PS341 on bone marrow stromal cells (BMSC) in multiple myeloma. BMSCs normally secrete interleukin-6, which induces growth and apoptosis-resistence of multiple myeloma cells. PS341 decreases the adherence of multiple myeloma cells to BMSCs and inhibits interleukin-6 secretion by the latter, since it depends on NFKB activation. Those effects contribute to the overall positive effects in the treatment of multiple myeloma with PS-341 [169].

Induction of apoptosis in vivo by proteasome inhibitors is not limited to tumors. Local application of the proteasome inhibitor MG132 resulted in significant inhibition (by 74\%) of intimal hyperplasia in a balloon injury model in the rat carotid artery. This effect was accompanied by decreased proliferation, reduced infiltration of macrophages, and increased apoptosis [170].

\section{Combination of proteasome inhibitors with other proapoptotic agents}

Proteasome inhibitors may be even more beneficial, when combined with already used chemotherapeutics, immunotherapy and radiotherapy. PS341 was shown to induce radiosensitization of various cancer cell lines and in vivo [171,172]. Combinations of proteasome inhibitors with several chemotherapeutics have shown synergistic interaction in vitro and in vivo. Among the various combinations used were e.g. PSI with paclitaxel in a human lung adenocarcinoma cell line (LC-2-AD) [173], PSI with taxol and cisplatinium in human myeloid leukaemia cell lines [73], PS341 with different topoisomerase inhibitors, such as $\mathrm{SN}-38$ and CPT11 in vitro and in vivo in nude mice $[174,87]$ and PS341 with gemictabine, a pyrimidine analogue in vitro and in vivo in nude mice using human pancreatic cancer xenografts [173,81], MG132 with anti-FAS antibody in human vascular smooth muscle cells [101], lactacystin with TNF $\alpha$ in chemo- and radioresistant human chronic lymphocytic leukaemia lymphocytes [78], TNF $\alpha$ with various proteasome inhibitors in human adenocarcinoma in vitro [175] and TNF $\alpha$ with PSI in vivo in C-26 colon carcinoma [176].

However, before combining proteasome inhibitors with other drugs a detailed evaluation of the involved biochemical pathways must be made, since sometimes there are no benefits of such combination or even antagonistic effects. For example, pretreatment with retinoic acid inhibits the proapoptogenic effects of PSI in the murine L1210 leukemia cells, probably by inducing their differentiation and block in the cell cycle. More differentiated and less proliferating cells are more resistant to the proapoptotic action of proteasome inhibitors [177]. Another example of antagonism is shown by the fact that PS341 inhibited gelandamycin-induced apoptosis in HL60 and K562 Bcr-Abl overexpressing cells [162]. Finally, pretreatment of COS-7 cells with proteasome inhibitors prevented many features of staurosporine-induced apoptosis including reduced caspase activation [178].

Sometimes even proven combinations are not showing expected synergism of action, as is the case with TNF $\alpha$ combined with proteasome inhibitors in melanoma cells [179].

\section{Resistance to the proapoptotic action of proteasome inhibitors}

Resistance to the action of a chemotherapeutic drug is always a major concern in cancer treatment. Unfortunately, cancer cells can also become 
resistant to proteasome inhibitors. Murine EL-4 leukemia cells grown in the presence of NLVS - a vinyl sulfone proteasome inhibitor have developed resistence to their proapoptogenic and antiproliferative action [180]. It was originally postulated, that the adapted EL-4 cells lacked active proteasomes and that upregulated tripeptidyl peptidase II replaced the $26 \mathrm{~S}$ proteasome in the function of degrading cellular proteins [180,181]. The possibility, that such a complicated proteolytic machinery as the proteasome can be redundant seemed unlikely, even after publication of another report, claiming that TPPII can replace some functions of the proteasome [182]. A compound used in that study and claimed to be a selective TPPII inhibitor AAF-cmk is also proteasome inhibitor and does not show any synergism with a typical proteasome inhibitor such as PSI [183]. Moreover, it was recently shown, that adapted EL4 cells just become resistant to NLVS, but they do contain active proteasome sensitive to different and more specific inhibitors including epoxomicin and PS-341. Adapted cells are not more sensitive to AAF-cmk than control cells which puts in doubt the role of TPPII in resistance to proteasome inhibitors [184]. Another group has found, that Burkitt's lymphoma cells with constitutively activated c-myc are resistant to apoptosis and do not accumulate ubiquitin conjugates in response to otherwise toxic doses of inhibitors of the proteasome. A possible explanation to this resistance could be by the fact, that they have upregulated deubiquitinating enzymes and TPPII. Moreover, apoptosis was induced in those cells by inhibition of TPPII [185]. It was shown recently, that human multiple myeloma cell lines may become resistant to PS-341 without upregulation of neither TPPII nor the multidrug resistance pomp (Philipp Steiner, personal communication). Moreover, Drosophila S2 cells with decreased proteasome activity due to RNAi of selected subunits become resistant to the proapoptotic action of lactacystin, epoxomicin and PS-341 implying the development of some compensatory mechanisms. Those cells did not show upregulation of TPPII or lysosomal cathepsin $\mathrm{D}$ [186]. The exact nature of mechanisms compensating for the impairment of proteasome function remains a mystery, however it is almost certain that TPPII alone can not be the culprit. TPPII does however perform the important role downstream of the proteasome in the full degradation of cytosolic proteins into free amino acids, becasue it is responsible of cleaving oligopeptides generated by the proteasome into tripeptides, which are further trimmed into amino acids by several exopeptidases [187].

Resistance to proteasome inhibitors can be also induced by the overexpression of caspase-3s in 293 cells, otherwise sensitive to those inhibitors. Caspase $3 \mathrm{~s}$ is a naturally occurring short caspase-3 variant (caspase-3s) that is resulted from alternative mRNA splicing which is coexpressed with full length caspase 3 in all human tissues examined and in several cancer cell lines. Curiously, proteasome inhibition stabilized the level of caspase-3s what may indicate the natural line of defense against the induction of apoptosis [188]. It is therefore possible, that some cells are very sensible to the impairment of proteasome function what triggers apoptotic response, however if this response is blocked, other proteolytic pathways may be sufficient to allow the survival and even proliferation of cells in situations of impaire dproteasome function.

\section{Concluding remarks}

It is difficult to outline a single and clearly defined role of the ubiquitin- and proteasome system in apoptosis. The evidence gathered in this review clearly shows, that proteasome inhibitors in some systems induce apoptosis or sensitize to apoptosis induced by other agents, while in other systems they do not. Moreover, in various instances they prevent apoptosis induced by other agents. Fortunately enough, rapidly proliferating cells with abnormal phenotypes i.e. cancer cells are the most sensitive to the proapoptogenic action of proteasome inhibitors, while normal cells are not or less sensitive, even when they form highly proliferating populations, such as bone marrow cells or epithelia. This makes proteasome inhibitors very promising agents in cancer therapy, and they are already used in clinical trials [189,57]. The ability of proteasome inhibitors to induce apoptosis in certain cell types can be also exploited in the treatment of other pathological conditions [50] [190]. They also have potential to be used as 
immunosupressant drugs possibly useful in organ transplantation recipients [191].

At present it is difficult to establish, what are the exact reasons why some cells are sensitive to proteasome inhibition and some are not. A general explanation may be given if we assume, that instead of talking about "apoptosis" in general, we must also consider many "apoptoses" i.e. apoptosis in the context of the particular cell type and particular proapoptotic stimuli. While the morphological changes are similar and the execution phase of apoptosis is generally common, there are various and disparate ways of apoptosis induction. Regulated protein degradation mediated by the proteasomes evidently play distinct and well defined roles on the various pathways of leading to apoptosis induction. The forecoming years will definitely see further research in this exciting field, where the two most important proteolytic pathways in the cytoplasm proteasomes and caspases - meet in a struggle for life and death of a cell, and often of the entire organism.

\section{References}

1. Mayer R. J., The meteoric rise of regulated intracellular proteolysis, Nat. Rev. Mol. Cell Biol., 1: $145-148,2000$

2. Rubin D. M., Finley D., Proteolysis. The proteasome: a protein-degrading organelle?, Curr. Biol., 5: 854-858, 1995

3. Rock K. L., Gramm C., Rothstein L., Clark K., Stein R., Dick L., Hwang D., Goldberg A. L., Inhibitors of the proteasome block the degradation of most cell proteins and the generation of peptides presented on MHC class I molecules, Cell, 78: 761-71, 1994

4. Hochstrasser M., Johnson P. R., Arendt C. S., Amerik A. Y., Swaminathan S., Swanson R., Li S. J., Laney J., Pals-Rylaarsdam R., Nowak J., Connerly P. L., The Saccharomyces cerevisiae ubiquitin-proteasome system, Philos. Trans. R. Soc. Lond B Biol. Sci., 354: 1513-1522, 1999

5. Drexler H. C. A., Programmed cell death and the proteasome, Apoptosis, 3: 1-7, 1998

6. Orlowski R. Z., The role of the ubiquitinproteasome pathway in apoptosis., Cell Death Differ, 6: 303_313-1999

7. Grimm L. M., Osborne B. A., Apoptosis and the proteasome, Results Probl Cell Differ, 23: 209-28, 1999

8. Wojcik C., Proteasomes in apoptosis: villains or guardians?, Cell Mol. Life Sci., 56: 908-917, 1999
9. Jesenberger V., Jentsch S., Deadly encounter: ubiquitin meets apoptosis, Nat. Rev. Mol. Cell Biol., 3: 112-121, 2002

10. Etlinger J. D., Goldberg A. L., A soluble ATPdependent proteolytic system responsible for the degradation of abnormal proteins in reticulocytes, Proc. Natl. Acad. Sci. U. S. A, 74: 54-58, 1977

11. Hershko A., Ciechanover A., Varshavsky A., Basic Medical Research Award. The ubiquitin system, Nat. Med., 6: 1073-1081, 2000

12. Wu R. S., Kohn K. W., Bonner W. M., Metabolism of ubiquitinated histones, J. Biol. Chem., 256: 591620, 1981

13. Strous G. J., Govers R., The ubiquitin-proteasome system and endocytosis, J. Cell Sci., 112 : 1417-23, 1999

14. Finley D., Bartel B., Varshavsky A., The tails of ubiquitin precursors are ribosomal proteins whose fusion to ubiquitin facilitates ribosome biogenesis, Nature, 338: 394-401, 1989

15. Ciechanover A., Hod Y., Hershko A., A heat-stable polypeptide component of an ATP-dependent proteolytic system from reticulocytes, Biochem. Biophys. Res. Commun., 81: 1100-5, 1978

16. Hershko A., Ciechanover A., The ubiquitin system, Апnи. Rev. Biochem., 67: 425-79, 1998

17. Ciechanover A., Breitschopf K., Hatoum O. A., Bengal E., Degradation of MyoD by the ubiquitin pathway: regulation by specific DNA-binding and identification of a novel site for ubiquitination, Mol. Biol. Rep., 26: 59- 64, 1999

18. Pickart C. M., Mechanisms underlying ubiquitination, Annu. Rev. Biochem., 70: 503-533, 2001

19. Pickart C. M., Ubiquitin in chains, Trends Biochem. Sci., 25: 544-548, 2000

20. Coffino P., Antizyme, a mediator of ubiquitinindependent proteasomal degradation, Biochimie, 83: 319-323, 2001

21. Kamitani T., Kito K., Fukuda-Kamitani T., Yeh E. T., Targeting of NEDD8 and its conjugates for proteasomal degradation by NUB1, J. Biol. Chem., 276: 46655-46660, 2001

22. Andrea A. D., Pellman D., Deubiquitinating enzymes: a new class of biological regulators, Crit. Rev. Biochem. Mol. Biol., 33: 337-52, 1998

23. Wilkinson K. D., Regulation of ubiquitin-dependent processes by deubiquitinating enzymes, FASEB J., 11: $1245-56,1997$

24. Hendil K. B., The 19 S multicatalytic "prosome" proteinase is a constitutive enzyme in HeLa cells, Biochem. Intl., 17: 471-7, 1988

25. Arrigo A. P., Tanaka K., Goldberg A. L., Welch W. J., Identity of the $19 \mathrm{~S}$ 'prosome' particle with the large multifunctional protease complex of mammalian cells (the proteasome), Nature, 331: 1924, 1988 
26. Bochtler M., Ditzel L., Groll M., Hartmann C., Huber R., The proteasome, Annu. Rev. Biophys. Biomol. Struct., 28: 295-317, 1999

27. Demartino G. N., Slaughter C. A., The proteasome, a novel protease regulated by multiple mechanisms, J. Biol. Chem., 274: 22123-6, 1999

28. Groll M., Ditzel L., Lowe J., Stock D., Bochtler M., Bartunik H. D., Huber R., Structure of $20 \mathrm{~S}$ proteasome from yeast at 2.4 A resolution [see comments], Nature, 386: 463-71, 1997

29. Wilk S., Orlowski M., Cation-sensitive neutral endopeptidase: isolation and specificity of the bovine pituitary enzyme., J. Neurochem., 35: 1172-82, 1980

30. Wilk S., Orlowski M., Evidence that pituitary cation-sensitive neutral endopeptidase is a multicatalytic protease complex, J. Neurochem., 40: 842-9, 1983

31. Orlowski M., Wilk S., Catalytic activities of the 20 $\mathrm{S}$ proteasome, a multicatalytic proteinase complex, Arch. Biochem. Biophys., 383: 1-16, 2000

32. Lowe J., Stock D., Jap B., Zwickl P., Baumeister W., Huber R., Crystal structure of the 20S proteasome from the archaeon T. acidophilum at $3.4 \mathrm{~A}$ resolution [see comments], Science, 268: 533-9, 1995

33. Fenteany G., Standaert R. F., Lane W. S., Choi S., Corey E. J., Schreiber S. L., Inhibition of proteasome activities and subunit-specific amino-terminal threonine modification by lactacystin, Science, 268: 726-31, 1995

34. Arendt C. S., Hochstrasser M., Identification of the yeast $20 \mathrm{~S}$ proteasome catalytic centers and subunit interactions required for active-site formation, Proc. Natl. Acad. Sci. U S A, 94: 7156-61, 1997

35. Fruh K., Gossen M., Wang K., Bujard H., Peterson P. A., Yang Y., Displacement of housekeeping proteasome subunits by MHC-encoded LMPs: a newly discovered mechanism for modulating the multicatalytic proteinase complex, EMBO J., 13: 3236-44, 1994

36. Fruh K., Yang Y., Antigen presentation by MHC class I and its regulation by interferon gamma, Curr. Opin. Immunol., 11: 76-81, 1999

37. Kloetzel P. M., Soza A., Stohwasser R., The role of the proteasome system and the proteasome activator PA28 complex in the cellular immune response, Biol. Chem., 380: 293-7, 1999

38. Demartino G. N., Proske R. J., Moomaw C. R., Strong A. A., Song X., Hisamatsu H., Tanaka K., Slaughter C. A., Identification, purification, and characterization of a PA700-dependent activator of the proteasome, J. Biol. Chem., 271: 3112-8, 1996

39. Glickman M. H., Rubin D. M, Coux O., Wefes I., Pfeifer G., Cjeka Z., Baumeister W., Fried V. A., Finley D., A subcomplex of the proteasome regulatory particle required for ubiquitin-conjugate degradation and related to the COP9-signalosome and eIF3, Cell, 94: 615-23, 1998
40. Glickman M. H., Rubin D. M., Fried V. A., Finley D., The regulatory particle of the Saccharomyces cerevisiae proteasome, Mol. Cell. Biol., 18: 3149-62, 1998

41. Dubiel W., Pratt G., Ferrell K., Rechsteiner M., Purification of an $11 \mathrm{~S}$ regulator of the multicatalytic proteinase., J. Biol. Chem., 267: 22369-22377, 1992

42. Ma C. P., Slaughter C. A., Demartino G. N., Identification, purification, and characterization of a protein activator (PA28) of the $20 \mathrm{~S}$ proteasome (macropain), J. Biol. Chem., 267: 10515- 10523, 1992

43. Rechsteiner M., Realini C., Ustrell V., The proteasome activator $11 \mathrm{~S}$ REG (PA28) and class I antigen presentation, Biochem. J., 345 Pt 1: 1-15, 2000

44. Tanahashi N., Yokota K., Ahn J. Y., Chung C. H., Fujiwara T., Takahashi E., Demartino G. N., Slaughter C. A., Toyonaga T., Yamamura K., Shimbara N., Tanaka K., Molecular properties of the proteasome activator PA28 family proteins and gamma-interferon regulation, Genes Cells, 2: 195-211, 1997

45. Chu-Ping M., Slaughter C. A., Demartino G. N., Purification and characterization of a protein inhibitor of the 20S proteasome (macropain), Biochim. Biophys. Acta, 1119: 303-11, 1992

46. Scherrer K., Prosomes, subcomplexes of untranslated mRNP, Molec. Biol. Rep., 14: 1-9, 1990

47. Pamnani V., Haas B., Puhler G., Sanger H. L., Baumeister W., Proteasome-associated RNAs are non-specific, Eur. J. Biochem., 225: 511-9, 1994

48. Seemuller E., Lupas A., Stock D., Lowe J., Huber R., Baumeister W., Proteasome from Thermoplasma acidophilum: a threonine protease, Science, 268: 579582,1995

49. Lee D. H., Goldberg A. L., Proteasome inhibitors: valuable new tools for cell biologists., Trends Cell Biol, 8: 397-403, 1998

50. Wojcik C., Inhibition of the proteasome as a therapeutic approach, Drug Discov. Today, 4: 188-192, 1999

51. Kisselev A. F., Goldberg A. L., Proteasome inhibitors: from research tools to drug candidates, Chem. Biol., 8: 739-758, 2001

52. Orlowski M., The multicatalytic proteinase complex, a major extralysosomal proteolytic system, Biochemistry, 29: 10289-97, 1990

53. Figueiredo-Pereira M. E., Berg K. A, Wilk S., A new inhibitor of the chymotrypsin-like activity of the multicatalytic proteinase complex (20S proteasome) induces accumulation of ubiquitin-protein conjugates in a neuronal cell, J. Neurochem., 63: 1578-81, 1994

54. Spaltenstein A., Leban J. J., Huang J. J., Reinhardt K. R., Viveros O. H., Sigafoos J., Crouch R., Design and synthesis of novel protease inhibitors. Tripeptide a',b'-epoxyketones as nanomolar inactivators of the proteasome., Tetrahedron Lett., 37: 1343-6, 1996 
55. Iqbal M., Chatterjee S., Kauer J. C., Das M., Messina P., Freed B., Biazzo W., Siman R., Potent inhibitors of proteasome, J. Med. Chem., 38: 2276-7, 1995

56. Lum R. T., Kerwar S. S., Meyer S. M., Nelson M. G., Schow S. R., Schiffman D., Wick M. M., Joly A., A new class of proteasome inhibitors that prevent NFkB activation., Biochem. Pharmacol., 55: 13911397, 1998

57. Adams J., Proteasome inhibition in cancer: development of PS-341, Semin. Oncol., 28: 613-619, 2001

58. Meng L., Mohan R., Kwok B. H., Elofsson M., Sin N., Crews C. M., Epoxomicin, a potent and selective proteasome inhibitor, exhibits in vivo antiinflammatory activity, Proc. Natl. Acad. Sci. USA, 96: 10403-10408, 1999

59. Meng L., Kwok B. H., Sin N., Crews C. M., Eponemycin exerts its antitumor effect through the inhibition of proteasome function, Cancer Res, 59: 2798-801, 1999

60. Kroll M., Arenzana-Seisdedos F., Bachelerie F., Thomas D., Friguet B., Conconi M., The secondary fungal metabolite gliotoxin targets proteolytic activities of the proteasome, Chem. Biol., 6: 689-98, 1999

61. Nam S., Smith D. M., Dou Q. P., Tannic Acid Potently Inhibits Tumor Cell Proteasome Activity, Increases p27 and Bax Expression, and Induces G(1) Arrest and Apoptosis, Cancer Epidemiol. Biomarkers Prev., 10: 1083-1088, 2001

62. Andre P., Groettrup M., Klenerman P., de Giuli R., Booth B. L., Jr., Cerundolo V., Bonneville M., Jotereau F., Zinkernagel R. M., Lotteau V., An inhibitor of HIV-1 protease modulates proteasome activity, antigen presentation, and $\mathrm{T}$ cell responses, Proc. Natl. Acad. Sci. USA, 95: 13120-4, 1998

63. Rao S., Porter D. C., Chen X., Herliczek T., Lowe M., Keyomarsi K., Lovastatin-mediated G1 arrest is through inhibition of the proteasome, independent of hydroxymethyl glutaryl-CoA reductase, Proc. Natl. Acad. Sci. USA, 96: 7797-802, 1999

64. Wojcik C., Bury M., Stoklosa T., Giermasz A., Feleszko W., Mlynarczuk I., Pleban E., Basak G., Omura S., Jakobisiak M., Lovastatin and simvastatin are modulators of the proteasome, Int. J. Biochem. Cell Biol., 32: 957-965, 2000

65. Isoe T., Naito M., Hirai R., Tsuruo T., Inhibition of ubiquitin-ATP-dependent proteolysis and ubiquitination by cisplatin, Anticancer Res., 11: 1905-9, 1991

66. Isoe T., Naito M., Shirai A., Hirai R., Tsuruo T., Inhibition of different steps of the ubiquitin system by cisplatin and aclarubicin, Biochim. Biophys. Acta, 1117: 131-5, 1992
67. Figueiredo-Pereira M. E., Chen W. E., Li J., Johdo O., The antitumor drug aclacinomycin A, which inhibits the degradation of ubiquitinated proteins, shows selectivity for the chymotrypsinlike activity of the bovine pituitary $20 \mathrm{~S}$ proteasome, J. Biol. Chem., 271: 16455-9, 1996

68. Kiyomiya K., Matsuo S., Kurebe M., Proteasome is a carrier to translocate doxorubicin from cytoplasm into nucleus, Life Sci., 62: 1853-60, 1998

69. Piccinini M., Tazartes O., Mezzatesta C., Ricotti E., Bedino S., Grosso F., Dianzani U., Tovo P. A., Mostert M., Musso A., Rinaudo M. T., Proteasomes are a target of the anti-tumour drug vinblastine, Biochem. J., 356: 835-841, 2001

70. Schwartz L. M., Myer A., Kosz L., Engelstein M., Maier C., Activation of polyubiquitin gene expression during developmentally programmed cell death, Neuron, 5: 411-9, 1990

71. Imajoh-Ohmi S., Kawaguchi T., Sugiyama S., Tanaka K., Omura S., Kikuchi H., Lactacystin, a specific inhibitor of the proteasome, induces apoptosis in human monoblast U937 cells, Biochem Biophys Res Comm, 217: 1070-7, 1995

72. Almond J. B., Snowden R. T., Hunter A., Dinsdale D., Cain K., Cohen G. M., Proteasome inhibitor-induced apoptosis of B-chronic lymphocytic leukaemia cells involves cytochrome c release and caspase activation, accompanied by formation of an approximately $700 \mathrm{kDa}$ Apaf-1 containing apoptosome complex, Leukemia, 15: 1388-1397, 2001

73. Soligo D., Servida F., Delia D., Fontanella E., Lamorte G., Caneva L. Fumiatti R., Lambertenghi D. G., The apoptogenic response of human myeloid leukaemia cell lines and of normal and malignant haematopoietic progenitor cells to the proteasome inhibitor PSI, Br. J. Haematol., 113: 126-135, 2001

74. Bold R. J., Virudachalam S., McConkey D. J., Chemosensitization of pancreatic cancer by inhibition of the $26 \mathrm{~S}$ proteasome, J. Surg. Res., 100: 11-17, 2001

75. Lee M., Hyun D. H., Marshall K. A., Ellerby L. M., Bredesen D. E., Jenner P., Halliwell B., Effect of overexpression of $\mathrm{Bcl}-2$ on cellular oxidative damage, nitric oxide production, antioxidant defenses, and the proteasome, Free Radic. Biol. Med., 31: 1550-1559, 2001

76. Traenckner E. B., Wilk S. Baeuerle P. A., A proteasome inhibitor prevents activation of NFkappa B and stabilizes a newly phosphorylated form of I kappa B-alpha that is still bound to NFkappa B, EMBO J., 13: 5433-41, 1994 
77. Wang C. Y., Mayo M. W., Baldwin A. S. Jr., TNFand cancer therapy-induced apoptosis: potentiation by inhibition of NFkB., Science, 274: 787-789, 1996

78. Delic J., Masdehors P., Omura S., Cosset J. M., Dumont J., Binet J. L., Magdelenat H., The proteasome inhibitor lactacystin induces apoptosis and sensitizes chemo- and radioresistant human chronic lymphocytic leukaemia lymphocytes to TNFalpha-initiated apoptosis, Br. J. Canc., 77: 1103-7, 1998

79. Fujita E., Mukasa T., Tsukahara T., Arahata K., Omura S., Momoi T., Enhancement of CPP32-like activity in the TNF-treated U937 cells by the proteasome inhibitors, Biochem Biophys. Res. Comm., 224: 74-9, 1996

80. Fujihara S., Ward C., Dransfield I., Hay R., Uings I., Hayes B., Farrow S., Haslett C., Rossi A., Inhibition of nuclear factor- $\kappa \mathrm{B}$ activation un-masks the ability of TNF- $\alpha$ to induce human eosinophil apoptosis, Eur. J. Immunol., 32: 457-466, 2002

81. Franco A. V., Zhang X. D., Van Berkel E., Sanders J. E., Zhang X. Y., Thomas W. D., Nguyen T., Hersey P., The role of NF-kappa B in TNF-related apoptosis-inducing ligand (TRAIL)- induced apoptosis of melanoma cells, J. Immunol., 166: 5337 5345, 2001

82. Yabe T., Wilson D., Schwartz J. P., NF\{kappa\}B activation is required for the neuroprotective effects of pigment epithelium-derived factor (PEDF) on cerebellar granule neurons, J . Biol. Chem., 2001

83. Elliott P. J., Pien C. S., McCormack T. A., Chapman I. D., Adams J., Proteasome inhibition: A novel mechanism to combat asthma, J. Allergy Clin. Immunol., 104: 294-300, 1999

84. Wojcik C., Schroeter D., Stoehr M., Wilk S., Paweletz N., An inhibitor of the chymotrypsin-like activity of the multicatalytic proteinase complex (20S proteasome) induces arrest in G2-phase and metaphase in HeLa cells, Europ. J. Cell. Biol., 70: 172-8, 1996

85. Machiels B. M., Henfling M. E., Gerards W. L., Broers J. L., Bloemendal H., Ramaekers F. C., Schutte B., Detailed analysis of cell cycle kinetics upon proteasome inhibition, Cytometry, 28: 243-252, 1997

86. Hershko A., Roles of ubiquitin-mediated proteolysis in cell cycle control, Curr. Opin. Cell Biol., 9: 788-99, 1997

87. Shah S. A., Potter M. W., McDade T. P., Ricciardi R., Perugini R. A., Elliott P. J., Adams J., Callery M. P., 26S proteasome inhibition induces apoptosis and limits growth of human pancreatic cancer, J. Cell Biochem., 82: 110-122, 2001

88. Shen Y., White E., p53-dependent apoptosis pathways, Adv. Cancer Res., 82: 55-84, 2001
89. Wang X. W., Role of p53 and apoptosis in carcinogenesis, Anticancer Res., 19: 4759-4771, 1999

90. Burns T. F., El Deiry W. S., The p53 pathway and apoptosis, J. Cell Physiol., 181: 231-239, 1999

91. Fang S., Jensen J. P., Ludwig R. L., Vousden K. H., Weissman A. M., Mdm2 is a RING fingerdependent ubiquitin protein ligase for itself and p53, J. Biol. Chem., 275: 8945-8951, 2000

92. Cho J. W., Park J. C., Lee J. C., Kwon T. K., Park J. W., Baek W. K., Suh S. I., Suh M. H., The levels of MDM2 protein are decreased by a proteasomemediated proteolysis prior to caspase-3-dependent pRb and PARP cleavages, J. Korean Med. Sci., 16: 135-139, 2001

93. MacLaren A. P., Chapman R. S., Wyllie A. H., Watson C. J., p53-dependent apoptosis induced by proteasome inhibition in mammary epithelial cells, Cell Death. Differ., 8: 210-218, 2001

94. Herrmann J. L., Briones F. Jr., Brisbay S., Logothetis C. J., McDonnell T. J., Prostate carcinoma cell death resulting from inhibition of proteasome activity is independent of functional Bcl2 and p53, Oncogene, 17: 2889-99, 1998

95. An B., Goldfarb R. H., Siman R., Dou Q. P., Novel dipeptidyl proteasome inhibitors overcome $\mathrm{Bcl}-2$ protective function and selectively accumulate the cyclin-dependent kinase inhibitor p27 and induce apoptosis in transformed, but not normal, human fibroblasts, Cell Death Differ., 5: 1062-75, 1998

96. Wagenknecht B., Hermisson M., Eitel K. Weller M., Proteasome inhibitors induce p53/p21independent apoptosis in human glioma cells, Cell Physiol. Biochem., 9: 117-125, 1999

97. Seluanov A., Gorbunova V., Falcovitz A., Sigal A., Milyavsky M., Zurer I., Shohat G., Goldfinger N., Rotter V., Change of the death pathway in senescent human fibroblasts in response to DNA damage is caused by an inability to stabilize p53, Mol. Cell Biol., 21: 1552-1564, 2001

98. Fukazawa T., Fujiwara T., Uno F., Teraishi F., Kadowaki Y., Itoshima T., Takata Y., Kagawa S., Roth J. A., Tschopp J., Tanaka N., Accelerated degradation of cellular FLIP protein through the ubiquitin- proteasome pathway in p53-mediated apoptosis of human cancer cells, Oncogene, 20: 5225-5231, 2001

99. Gregory M. A., Hann S. R., c-Myc proteolysis by the ubiquitin-proteasome pathway: stabilization of cMyc in Burkitt's lymphoma cells, Mol. Cell Biol., 20: 2423-2435, 2000

100. Tani E., Kitagawa H., Ikemoto H., Matsumoto T., Proteasome inhibitors induce Fas-mediated apoptosis by c-Myc accumulation and subsequent induction of FasL message in human glioma cells, FEBS Lett., 504: 53-58, 2001 
101. Kim K., Proteasome inhibitors sensitize human vascular smooth muscle cells to Fas (CD95)mediated death, Biochem. Biophys. Res. Commun., 281: 305-310, 2001

102.Suzuki Y., Nakabayashi Y., Takahashi R., Ubiquitin-protein ligase activity of X-linked inhibitor of apoptosis protein promotes proteasomal degradation of caspase-3 and enhances its antiapoptotic effect in Fas-induced cell death, Proc. Natl. Acad. Sci. USA, 98: 8662-8667, 2001

103. Tenev T., Marani M., McNeish I., Lemoine N. R., Pro-caspase-3 overexpression sensitises ovarian cancer cells to proteasome inhibitors, Cell Death. Differ., 8: 256-264, 2001

104. Martin M. C., Dransfield I., Haslett C., Rossi A. G., Cyclic AMP regulation of neutrophil apoptosis occurs via a novel PKA- independent signaling pathway, J. Biol. Chem., 2001

105.Lee M. H., Hyun D. H., Jenner P., Halliwell B., Effect of proteasome inhibition on cellular oxidative damage, antioxidant defences and nitric oxide production, J. Neurochem., 78: 32-41, 2001

106.Pleban E., Bury M., Mlynarczuk I., Wojcik C., Effects of proteasome inhibitor PSI on neoplastic and non-transformed cell lines, Folia Histochem. Cytobiol., 39: 133-134, 2001

107.Sadoul R., Fernandez P. A., Quiquerez A. L., Martinou I., Maki M., Schroter M., Becherer J. D., Irmler M., Tschopp J., Martinou J. C., Involvement of the proteasome in the programmed cell death of NGF-deprived sympathetic neurons, EMBO J., 15: 3845-52, 1996

108. Grimm L. M., Goldberg A. L., Poirier G. G., Schwartz L. M., Osborne B. A., Proteasomes play an essential role in thymocyte apoptosis, EMBO J., 15: 3835-44, 1996

109. Tabata M., Tabata R., Grabowski D. R., Bukowski R. M., Ganapathi M. K., Ganapathi R., Roles of NF-kappaB and $26 \mathrm{~S}$ proteasome in apoptotic cell death induced by topoisomerase I and II poisons in human nonsmall cell lung carcinoma, $J$. Biol. Chem., 276: 8029-8036, 2001

110. Tanimoto Y., Kizaki H., Proteasome inhibitors block ras/ERK signaling pathway resulting in the downregulation of Fas ligand expression during activation-induced cell death in T cells, J. Biochem., 131: 319-326, 2002

111. Dallaporta B., Pablo M., Maisse C., Daugas E., Loeffler M., Zamzami N., Kroemer G., Proteasome activation as a critical event of thymocyte apoptosis, Cell Death. Differ., 7: 368-373, 2000

112. Distelhorst C. W., Recent insights into the mechanism of glucocorticosteroid-induced apoptosis, Cell Death. Differ., 9: 6-19, 2002
113. Wallace A. D., Cidlowski J. A., Proteasomemediated glucocorticoid receptor degradation restricts transcriptional signaling by glucocorticoids, J. Biol. Chem., 276: 42714-42721, 2001

114. Hirsch T., Dallaporta B., Zamzami N., Susin S. A., Ravagnan L., Marzo I., Brenner C., Kroemer G., Proteasome activation occurs at an early, premitochondrial step of thymocyte apoptosis, $J$. Immunol., 161: 35-40, 1998

115. Beyette J., Mason G. G., Murray R. Z., Cohen G. M., Rivett A. J., Proteasome activities decrease during dexamethasone-induced apoptosis of thymocytes, Biochem J, 332: 315-20, 1998

116. He H., Qi X. M., Grossmann J., Distelhorst C. W., c-Fos degradation by the proteasome. An early, Bcl2-regulated step in apoptosis, J. Biol. Chem., 273: 25015- 9, 1998

117. Ivanov V. N., Nikolic-Zugic J., Biochemical and kinetic characterization of the glucocorticoid-induced apoptosis of immature CD4+CD8+ thymocytes, Int. Immunol., 10: 1807-17, 1998

118. Grassilli E., Benatti F., Dansi P., Giammarioli A. M., Malorni W., Franceschi C., Desiderio M. A., Inhibition of proteasome function prevents thymocyte apoptosis: involvement of ornithine decarboxylase, Biochem. Biophys. Res. Comm., 250: 293-7, 1998

119. Gil-Gomez G., Berns A., Brady H. J., A link between cell cycle and cell death: Bax and Bcl-2 modulate Cdk2 activation during thymocyte apoptosis, EMBO J., 17: 7209-7218, 1998

120. Yang Y., Fang S., Jensen J. P., Weissman A. M., Ashwell J. D., Ubiquitin protein ligase activity of IAPs and their degradation in proteasomes in response to apoptotic stimuli, Science, 288: 874-877, 2000

121. Bannerman D. D., Tupper J. C., Ricketts W. A., Bennett C. F., Winn R. K., Harlan J. M., A constitutive cytoprotective pathway protects endothelial cells from lipopolysaccharide-induced apoptosis, J. Biol. Chem., 276: 14924-14932, 2001

122. Richter B. W., Duckett C. S., The IAP proteins: caspase inhibitors and beyond, Sci. STKE., 2000: E12000

123. Yang Y. L., Li X. M., The IAP family: endogenous caspase inhibitors with multiple biological activities, Cell Res., 10: 169-177, 2000

124. Mahoney J. A., Odin J. A., White S. M., Shaffer D., Koff A., Casciola-Rosen L., Rosen A., The human homologue of the yeast polyubiquitination factor $\mathrm{Ufd} 2 \mathrm{p}$ is cleaved by caspase 6 and granzyme B during apoptosis, Biochem. J., 361: 587-595, 2002

125. Koegl M., Hoppe T., Schlenker S., Ulrich H. D., Mayer T. U., Jentsch S., A novel ubiquitination factor, E4, is involved in multiubiquitin chain assembly, Cell, 96: 635-644, 1999 
126. Pizzuti A., Novelli G., Ratti A., Amati F., Mari A., Calabrese G., Nicolis S., Silani V., Marino B., Scarlato G., Ottolenghi S., Dallapiccola B., UFD1L, a developmentally expressed ubiquitination gene, is deleted in CATCH 22 syndrome, Hum. Mol. Genet., 6: 259- 265, 1997

127. Dai R. M., Li C. C., Valosin-containing protein is a multi-ubiquitin chain-targeting factor required in ubiquitin-proteasome degradation, Nat. Cell Biol., 3: 740-744, 2001

128. Ye Y., Meyer H. H., Rapoport T. A., The AAA ATPase Cdc48/p97 and its partners transport proteins from the ER into the cytosol, Nature, 414: 652-656, 2001

129. Araya R., Takahashi R., Nomura Y., Yeast twohybrid screening using constitutive-active caspase-7 as bait in the identification of PA28gamma as an effector caspase substrate, Cell Death. Differ., 9: 322-328, 2002

130. Li J., Gao X., Ortega J., Nazif T., Joss L., Bogyo M., Steven A. C., Rechsteiner M., Lysine 188 substitutions convert the pattern of proteasome activation by REGgamma to that of REGs alpha and beta, EMBO J., 20: 3359-3369, 2001

131. Murata S., Kawahara H., Tohma S., Yamamoto K., Kasahara M., Nabeshima Y., Tanaka K., Chiba T., Growth retardation in mice lacking the proteasome activator PA28gamma, J. Biol. Chem., 274: 38211-38215, 1999

132. Mullally J. E., Moos P. J., Edes K., Fitzpatrick F. A., Cyclopentenone prostaglandins of the $\mathrm{J}$ series inhibit the ubiquitin isopeptidase activity of the proteasome pathway, J. Biol. Chem., 276: 30366-30373, 2001

133. Migone T. S., Humbert M., Rascle A., Sanden D., D'Andrea A., Johnston J. A., The deubiquitinating enzyme DUB-2 prolongs cytokine-induced signal transducers and activators of transcription activation and suppresses apoptosis following cytokine withdrawal, Blood, 98: 1935-1941, 2001

134. Mimnaugh E. G., Kayastha G., McGovern N. B., Hwang S. G., Marcu M. G., Trepel J., Cai S. Y., Marchesi V. T., Neckers L., Caspase-dependent deubiquitination of monoubiquitinated nucleosomal histone H2A induced by diverse apoptogenic stimuli, Cell Death. Differ., 8: 1182-1196, 2001

135. Neves D. D., Rehen S. K., Linden R., Differentiation-dependent sensitivity to cell death induced in the developing retina by inhibitors of the ubiquitin-proteasome proteolytic pathway, Eur. J. Neurosci., 13: 1938-1944, 2001

136. Guzman M. L., Neering S. J., Upchurch D., Grimes B., Howard D. S., Rizzieri D. A., Luger S. M., Jordan C. T., Nuclear factor-kappaB is constitutively activated in primitive human acute myelogenous leukemia cells, Blood, 98: 2301-2307, 2001
137. Perletti L., Kopf E., Carre L., Davidson I., Coordinate regulation of RARgamma2, TBP, and TAFII135 by targeted proteolysis during retinoic acid-induced differentiation of F9 embryonal carcinoma cells, BMC. Mol. Biol., 2: 4-2001

138. Wójcik C., Schroeter D., Wilk S., Lamprecht J., Paweletz N., Ubiquitin-mediated proteolysis centers in HeLa cells: indication from studies of an inhibitor of the chymotrypsin-like activity of the proteasome, Eur. J. Cell Biol., 71: 311-8, 1996

139. Johnston J. A., Ward C. L., Kopito R. R., Aggresomes: a cellular response to misfolded proteins, J. Cell Biol., 143: 1883-98, 1998

140. Wojcik C., An inhibitor of the chymotrypsin-like activity of the proteasome (PSI) induces similar morphological changes in various cell lines, Folia Histochem. Cytobiol., 35: 211-214, 1997

141. Wojcik C., On the spatial organization of ubiquitindependent proteolysis in HeLa cells, Folia Histochem. Cytobiol., 35: 117-118, 1997

142. Rideout H. J., Larsen K. E., Sulzer D., Stefanis L., Proteasomal inhibition leads to formation of ubiquitin/alpha-synuclein- immunoreactive inclusions in PC1 2 cells, J. Neurochem., 78: 899-908, 2001

143. Bence N. F., Sampat R. M., Kopito R. R., Impairment of the ubiquitin-proteasome system by protein aggregation, Science, 292: 1552-1555, 2001

144. Volbracht C., Leist M., Kolb S. A., Nicotera P., Apoptosis in caspase-inhibited neurons, Mol. Med., 7: $36-48,2001$

145. Kuusisto E., Suuronen T., Salminen A., Ubiquitinbinding protein p62 expression is induced during apoptosis and proteasomal inhibition in neuronal cells, Biochem. Biophys. Res. Commun., 280: 223228, 2001

146. Hauser H. P., Bardroff M., Pyrowolakis G., Jentsch S., A giant ubiquitin-conjugating enzyme related to IAP apoptosis inhibitors, J. Cell Biol., 141: 1415-22, 1998

147. De Vrij F. M., Sluijs J. A., Gregori L., Fischer D. F., Hermens W. T., Goldgaber D., Verhaagen J., Van Leeuwen F. W., Hol E. M., Mutant ubiquitin expressed in Alzheimer's disease causes neuronal death, FASEB J., 15: 2680-2688, 2001

148. Tanaka Y., Engelender S., Igarashi S., Rao R. K., Wanner T., Tanzi R. E., Sawa A., Dawson L., Dawson T. M., Ross C. A., Inducible expression of mutant alpha-synuclein decreases proteasome activity and increases sensitivity to mitochondria-dependent apoptosis, Hum. Mol. Genet., 10: 919-926, 2001

149. Anton L. C., Schubert U., Bacik I., Princiotta M. F., Wearsch P. A. Gibbs J., Day P. M., Realini C, Rechsteiner M. C., Bennink J. R., Yewdell J. W., Intracellular localization of proteasomal degradation of a viral antigen, J. Cell Biol., 146: 113-124, 1999 
150. Jana N. R., Zemskov E. A., Wang G., Nukina N., Altered proteasomal function due to the expression of polyglutamine- expanded truncated N-terminal huntingtin induces apoptosis by caspase activation through mitochondrial cytochrome c release, Hum. Mol. Genet., 10: 1049-1059, 2001

151. Sherman M. Y., Goldberg A. L., Cellular defenses against unfolded proteins: a cell biologist thinks about neurodegenerative diseases, Neuron, 29: 15-32, 2001

152. Kopito R. R., Aggresomes, inclusion bodies and protein aggregation, Trends Cell Biol., 10: 524-530, 2000

153. Matsuzawa S., Takayama S., Froesch B. A., Zapata J. M., Reed J. C., p53-inducible human homologue of Drosophila seven in absentia (Siah) inhibits cell growth: suppression by Bag-1, EMBO J., 17: 2736-47, 1998

154. Sondermann H., Scheufler C., Schneider C., Hohfeld J., Hartl F. U., Moarefi I., Structure of a Bag/Hsc70 complex: convergent functional evolution of Hsp70 nucleotide exchange factors, Science, 291: 1553-1557, 2001

155. Luders J., Demand J., Hohfeld J., The ubiquitinrelated BAG-1 provides a link between the molecular chaperones Hsc70/Hsp70 and the proteasome, J. Biol. Chem., 275: 4613-4617, 2000

156. Murata S., Minami Y., Minami M., Chiba T., Tanaka K., CHIP is a chaperone-dependent E3 ligase that ubiquitylates unfolded protein, EMBO Rep., 2: 1133-1138, 2001

157. Demand J., Alberti S., Patterson C., Hohfeld J., Cooperation of a ubiquitin domain protein and an E3 ubiquitin ligase during chaperone/proteasome coupling, Curr. Biol., 11: 1569-1577, 2001

158. Fabunmi R. P., Wigley W. C., Thomas P. J., Demartino G. N., Activity and regulation of the centrosome-associated proteasome, J. Biol. Chem., 275: 409-413, 2000

159. Wigley W. C., Fabunmi R. P., Lee M. G., Marino C. R., Muallem S., Demartino G. N., Thomas P. J., Dynamic association of proteasomal machinery with the centrosome, J. Cell Biol., 145: 481-490, 1999

160. Ashok B. T., Kim E., Mittelman A., Tiwari R. K., Proteasome inhibitors differentially affect heat shock protein response in cancer cells, Int. J. Mol. Med., 8: 385-390, 2001

161. Kobayashi Y., Sobue G., Protective effect of chaperones on polyglutamine diseases, Brain Res. Bull., 56: 165-168, 2001

162. Nimmanapalli R., O'Bryan E., Bhalla K., Geldanamycin and its analogue 17-allylamino-17demethoxygeldanamycin lowers Bcr-Abl levels and induces apoptosis and differentiation of Bcr- Ablpositive human leukemic blasts, Cancer Res., 61: 1799-1804, 2001
163. Pajonk F., McBride W. H., The Proteasome in Cancer Biology and Treatment, Radiat. Res., 156: 447-459, 2001

164. Shah S. A., Potter M. W., Callery M. P., Ubiquitin proteasome pathway: implications and advances in cancer therapy, Surg. Oncol., 10: 43-52, 2001

165. Orlowski R. Z., Eswara J. R., Lafond-Walker A., Grever M. R., Orlowski M., Dang C. V., Tumor growth inhibition induced in a murine model of human Burkitt's lymphoma by a proteasome inhibitor, Cancer Res, 58: 4342-8, 1998

166. Stoklosa T., Golab J., Wójcik C., Jalili A., Marczak M., Giermasz A., Januszko P., Balkowiec E., Jakóbisiak M., Wilk S., Antitumor effect of proteasome inhibitor dependent on p53 induction and angiogenesis inhibition., Third Workshop on Proteasomes, Clermont-Ferrand, France, March1999

167. Sunwoo J. B., Chen Z., Dong G., Yeh N., Crowl B. C., Sausville E., Adams J., Elliott P., Van Waes C., Novel proteasome inhibitor PS-341 inhibits activation of nuclear factor- kappa B, cell survival, tumor growth, and angiogenesis in squamous cell carcinoma, Clin. Cancer Res., 7: 1419-1428, 2001

168. Sun J., Nam S., Lee C. S., Li B., Coppola D., Hamilton A. D., Dou Q. P., Sebti S. M., CEP1612, a dipeptidyl proteasome inhibitor, induces p21WAF1 and p27KIP1 expression and apoptosis and inhibits the growth of the human lung adenocarcinoma A-549 in nude mice, Cancer Res., 61: 1280-1284, 2001

169. Hideshima T., Richardson P., Chauhan D., Palombella V. J., Elliott P. J., Adams J., Anderson K. C., The proteasome inhibitor PS-341 inhibits growth, induces apoptosis, and overcomes drug resistance in human multiple myeloma cells, Cancer Res., 61: 3071-3076, 2001

170. Meiners S., Laule M., Rother W., Guenther C., Prauka I., Muschick P., Baumann G., Kloetzel P. M., Stangl K., Ubiquitin-proteasome pathway as a new target for the prevention of restenosis, Circulation, 105: 483-489, 2002

171. Pervan M., Pajonk F., Sun J. R., Withers H. R., McBride W. H., Molecular pathways that modify tumor radiation response, Am. J. Clin. Oncol., 24: 481-485, 2001

172. Russo S. M., Tepper J. E., Baldwin A. S. Jr., Liu R., Adams J., Elliott P., Cusack J. C. Jr., Enhancement of radiosensitivity by proteasome inhibition: implications for a role of NF-kappaB, Int. J. Radiat. Oncol. Biol. Phys., 50: 183-193, 2001

173. Oyaizu H., Adachi Y., Okumura T., Okigaki M., Oyaizu N., Taketani S., Ikebukuro K., Fukuhara S., Ikehara S., Proteasome inhibitor 1 enhances paclitaxel-induced apoptosis in human lung adenocarcinoma cell line, Oncol. Rep., 8: 825-829, 2001 
174. Cusack J. C. Jr., Liu R., Houston M., Abendroth K., Elliott P. J., Adams J., Baldwin A. S. Jr., Enhanced chemosensitivity to CPT-11 with proteasome inhibitor PS-341: implications for systemic nuclear factorkappaB inhibition, Cancer Res., 61: 3535-3540, 2001

175. Milligan S. A., Nopajaroonsri C., Inhibition of NFkappa B with proteasome inhibitors enhances apoptosis in human lung adenocarcinoma cells in vitro, Anticancer Res., 21 : 39-44, 2001

176. Golab J., Stoklosa T., Czajka A., Dabrowska A., Jakobisiak M., Zagozdzon R., Wojcik C., Marczak M., Wilk S., Synergistic antitumor effects of a selective proteasome inhibitor and TNF in mice, Anticancer Res., 20: 1717-1721, 2000

177. Wojcik C., Mlynarczuk I., Hoser G., Kawiak J., Stoklosa T., Golab J., Wilk S., A combination of retinoic acid and proteasome inhibitors for the treatment of leukemias is potentially dangerous., Blood, 94: 1827-1828, 1999

178. Brophy V. A., Tavare J. M., Rivett A. J., Treatment of COS-7 cells with proteasome inhibitors or gammainterferon reduces the increase in caspase 3 activity associated with staurosporine-induced apoptosis, Arch. Biochem. Biophys., 397: 199-205, 2002

179. Stoklosa T., Wójcik C., Golab J., Giermasz A., Wilk S., Inhibition of proteasome, apoptosis and sensitization to tumour necrosis factor alpha: do they always go together?, Br. J. Cancer, 79: 375-376, 1999

180. Glas R., Bogyo M., McMaster J. S., Gaczynska M., Ploegh H. L., A proteolytic system that compensates for loss of proteasome function, Nature, 392: 618-622, 1998

181. Wang E. W., Kessler B. M., Borodovsky A., Cravatt B. F., Bogyo M., Ploegh H. L., Glas R., Integration of the ubiquitin-proteasome pathway with a cytosolic oligopeptidase activity, Proc. Natl. Acad. Sci. USA, 97: 9990-9995, 2000

182. Geier E., Pfeifer G., Wilm M., Lucchiari-Hartz M., Baumeister W., Eichmann K., Niedermann G., A giant protease with potential to substitute for some functions of the proteasome, Science, 283: 978-81, 1999
183. Bury M., Mlynarczuk I., Pleban E., Hoser G, Kawiak J., Wojcik C., Effects of an inhibitor of tripeptidyl peptidase II (Ala-Ala-Phechloromethylketone) and its combination with an inhibitor of the chymotrypsin-like activity of the proteasome (PSI) on apoptosis, cell cycle and proteasome activity in U937 cells, Folia Histochem. Cytobiol., 39: 131-132, 2001

184. Princiotta M. F., Schubert U., Chen W., Bennink J. R., Myung J., Crews C. M., Yewdell J. W., Cells adapted to the proteasome inhibitor 4-hydroxy- 5iodo-3- nitrophenylacetyl-Leu-Leu-leucinal-vinyl sulfone require enzymatically active proteasomes for continued survival, Proc. Natl. Acad. Sci. USA, 98: 513-518, 2001

185. Gavioli R., Frisan T., Vertuani S., Bornkamm G. W., Masucci M. G., c-myc overexpression activates alternative pathways for intracellular proteolysis in lymphoma cells, Nat. Cell Biol., 3: 283-288, 2001

186. Wojcik C., Demartino G. N., Analysis of Drosophila $26 \mathrm{~S}$ proteasome using RNA interference, J. Biol. Chem., 277: 6188-6197, 2002

187. Tomkinson B., Tripeptidyl peptidases: enzymes that count, Trends Biochem. Sci., 24: 355-359, 1999

188. Huang Y., Shin N. H., Sun Y., Wang K. K., Molecular cloning and characterization of a novel caspase-3 variant that attenuates apoptosis induced by proteasome inhibition, Biochem. Biophys. Res. Commun., 283: 762-769, 2001

189. Adams J., Palombella V. J., Sausville E. A., Johnson J., Destree A., Lazarus D. D., Maas J., Pien C. S., Prakash S., Elliott P. J., Proteasome inhibitors: a novel class of potent and effective antitumor agents, Cancer Res, 59: 2615-22, 1999

190. Wójcik C., Ubiquitin- and proteasome-dependent proteolytic pathway as an emerging theapeutic target, Emerging Therapeutic Targets, 4: 1-23, 2000

191. Luo H., Wu Y., Qi S., Wan X., Chen H., Wu J., A proteasome inhibitor effectively prevents mouse heart allograft rejection, Transplantation, 72: 196202, 2001 